\title{
Phosphorylation of the regulatory light chain of myosin in striated muscle: methodological perspectives
}

\author{
Haiyang $\mathrm{Yu}^{1} \cdot$ Samya Chakravorty $^{1} \cdot$ Weihua Song $^{1} \cdot$ Michael A. Ferenczi $^{1}$
}

Received: 18 November 2015 / Revised: 10 March 2016 / Accepted: 23 March 2016 / Published online: 15 April 2016

(C) The Author(s) 2016. This article is published with open access at Springerlink.com

\begin{abstract}
Phosphorylation of the regulatory light chain (RLC) of myosin modulates cellular functions such as muscle contraction, mitosis, and cytokinesis. Phosphorylation defects are implicated in a number of diseases. Here we focus on striated muscle where changes in RLC phosphorylation relate to diseases such as hypertrophic cardiomyopathy and muscular dystrophy, or age-related changes. RLC phosphorylation in smooth muscle and non-muscle cells are covered briefly where relevant. There is much scientific interest in controlling the phosphorylation levels of RLC in vivo and in vitro in order to understand its physiological function in striated muscles. A summary of available and emerging in vivo and in vitro methods is presented. The physiological role of RLC phosphorylation and novel pathways are discussed to highlight the differences between muscle types and to gain insights into disease processes.
\end{abstract}

Keywords Myosin - Regulatory light chain . Phosphorylation $\cdot$ Muscle contraction $\cdot$ Cardiovascular disease $\cdot$ Mechanochemistry

\section{Introduction}

Muscle contraction is driven by cyclical interaction between the thin filament protein actin and the thick

H. Yu and S. Chakravorty contributed equally in preparing and editing this manuscript.

Michael A. Ferenczi

m.ferenczi@ntu.edu.sg

1 Lee Kong Chian School of Medicine, Nanyang Technological University, Experimental Medicine Building, Level 3, 59

Nanyang Drive, Singapore 636921, Singapore filament protein myosin (Spudich 2001). The myosin family of proteins consists of more than two dozen distinct members (Ferenczi 2000; Pfitzer 2001). Myosin molecules are large (with a size of about $500 \mathrm{kDa}$ ), actin-binding ATPases, which act as molecular motors to provide a variety of movement-associated functions (Hartman and Spudich 2012; Spudich 2001; Syamaladevi et al. 2012). The 440-kDa Myosin II dimer, arranged into bipolar filaments, also known as thick filaments and containing 294 molecules (Atkinson and Stewart 1991), are the molecular motors responsible for muscle contraction. Myosin is the mechanochemical energy transducer, whose motor domain (or head) interacts with actin in the thin filament generating force, power, and shortening (Irving et al. 1992). Each myosin molecule is a hexameric protein containing two heavy chains (MHC) and four light chains. The stability of the $\alpha$-helical neck region of the S1 subfragment of each myosin heavy chain, also known as the lever arm region, is stabilized by two small light-chain proteins known as MYL1 (the alkali light chain, or the essential light chain, ELC, $\sim 25 \mathrm{kDa}$ ) and MYL2 (the regulatory light chain or RLC, $\sim 19 \mathrm{kDa}$ ) (Fig. 1). Both RLC and ELC have a structure closely related to that of the $\mathrm{EF}$ hand calcium binding protein family such as troponin $\mathrm{C}$ and calmodulin (Weeds 1969). However, unlike other EF hand proteins, RLC has only one $\mathrm{Ca}^{2+} / \mathrm{Mg}^{2+}$ binding $\mathrm{EF}$ hand domain between amino acids 37 and 48 (Collins 1976; Rayment et al. 1993). Thus, modulation of contraction by RLC phosphorylation has attracted much interest.

In striated muscles, activation of the myosin motor is mediated by thin-filament activation upon $\mathrm{Ca}^{2+}$ binding (on/off) to the actin-troponin-tropomyosin complex, not by RLC phosphorylation. RLC phosphorylation acts as a modulator and not as a switch in striated muscle (Sweeney et al. 1993; Szczesna 2003). In striated muscle, the RLC 


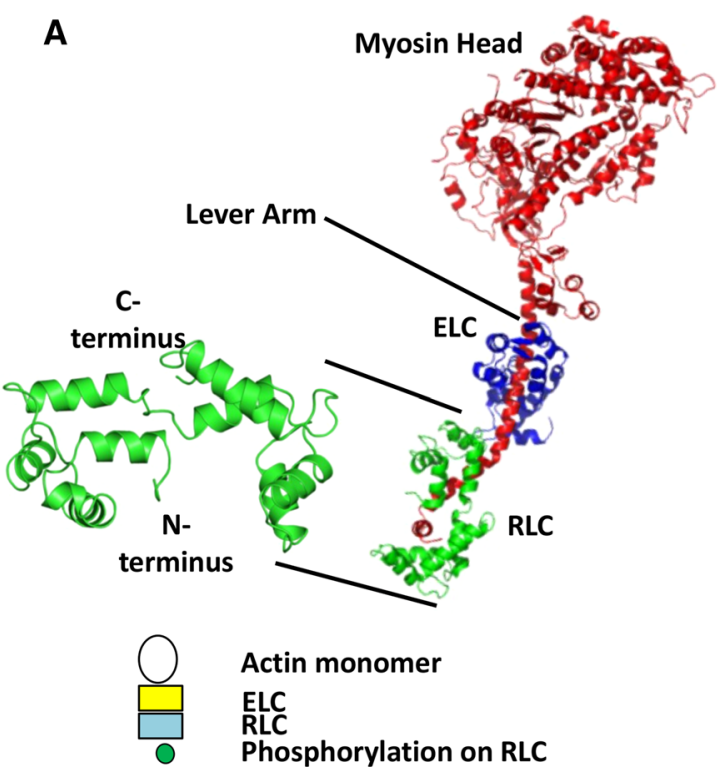

Fig. 1 RLC structure. a Chicken skeletal muscle isoform of RLC crystal structure with the helix-loop-helix showing four EF hands separated by loops (left). The N- and the C-termini are shown (PDB ID \# 2MYS; (Rayment et al. 1993) that wrap around the C-terminus side of the chicken skeletal myosin S1 sub-fragment (right) (Rayment et al. 1993). The $\mathrm{N}$-terminal amino acids 1-20 are missing from the crystal structure due to its flexibility (inherent disorder). The myosin head is the motor domain of the myosin molecule, the site of actin binding and contains the ATP hydrolysis pocket. The regulatory (RLC) and essential (ELC) light chains wrap around the lever arm conferring rigidity and stability to this long alpha-helical rod. b A simplified pictorial representation of the acto-myosin structure

phosphorylation state may function as the molecular memory of recent activation and contractile events by altering actomyosin interactions after repeated muscle activation (Kamm and Stull 2011; Matsumura et al. 2001; Scruggs and Solaro 2011). It has been proposed that phosphorylation induces movement of the myosin head away from the thick filament backbone toward the thin filament, thus increasing the probability of myosin attachment to actin (Colson et al. 2010; Levine et al. 1996). Below we describe the structure of RLC, the phosphorylation sites, and their functional significance.

\section{Structure, isoforms, phosphorylation sites, and function of RLC}

\section{Structure}

RLC ( 19 kDa) is a member of the EF-hand superfamily (which is a helix-loop-helix structural domain or motif found in a large family of calcium-binding proteins). The $\mathrm{N}$-terminal domain is similar in structure to calmodulin. $\mathrm{RLC}$ is non-covalently bound to the C-terminus of myosin

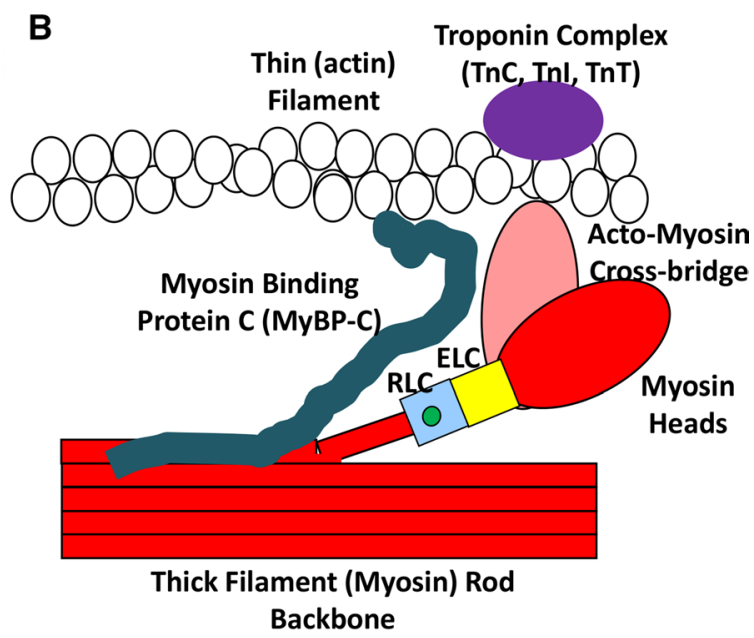

with RLC. The diagram shows the thick (myosin containing, red) filament backbone and thin (actin containing, white circles represent actin monomers) filament with an acto-myosin cross-bridge. The ELC (yellow box) and phosphorylated RLC (blue box) are in the neck region of the myosin heavy-chain monomer. The myosin head interacts weakly or strongly with the thin filament forming a cross-bridge structure. The Troponin complex (purple oval) on the thin filament comprising of troponin $\mathrm{C}$, troponin $\mathrm{I}$, and troponin $\mathrm{T}$ activate muscle contraction via calcium binding. Myosin binding protein $\mathrm{C}$ (MyBPC) (cyan) is associated with the thick filament backbone and also interacts with the thin filament (not drawn to scale). (Figure is modified from Fig. 6c of Farman et al. 2009)

S1 subfragment (Fig. 1b). The N-terminal domain of RLC wraps around the region between amino acids Asn 825 and Leu 842 at the C-terminal end of myosin S1. The C-terminal domain of RLC binds in the region between Glu 808 and Val 826 of myosin S1 (Rayment et al. 1993). The number of phosphorylatable serines of RLC differs between species and between tissues indicative of the presence of unique tissue-specific isoforms and phosphovariants, thus providing scope for a variety of functions. Although the isoforms of RLC are similar in structure, in particular in the divalent cation-binding sites and proximal phosphorylatable serines in both smooth and striated muscles, they have relatively low sequence similarity ( 57\%), suggesting functional differentiation (Scruggs and Solaro 2011).

\section{Isoforms}

Within the same tissue, there are multiple isoforms of RLC. In adult human skeletal muscle, there are three major RLC isoforms: two fast isoforms, namely type I (NCBI Accession \# P24732) and type II (NCBI Accession \# P02608), and one slow isoform (NCBI Accession \# P10916, same as 


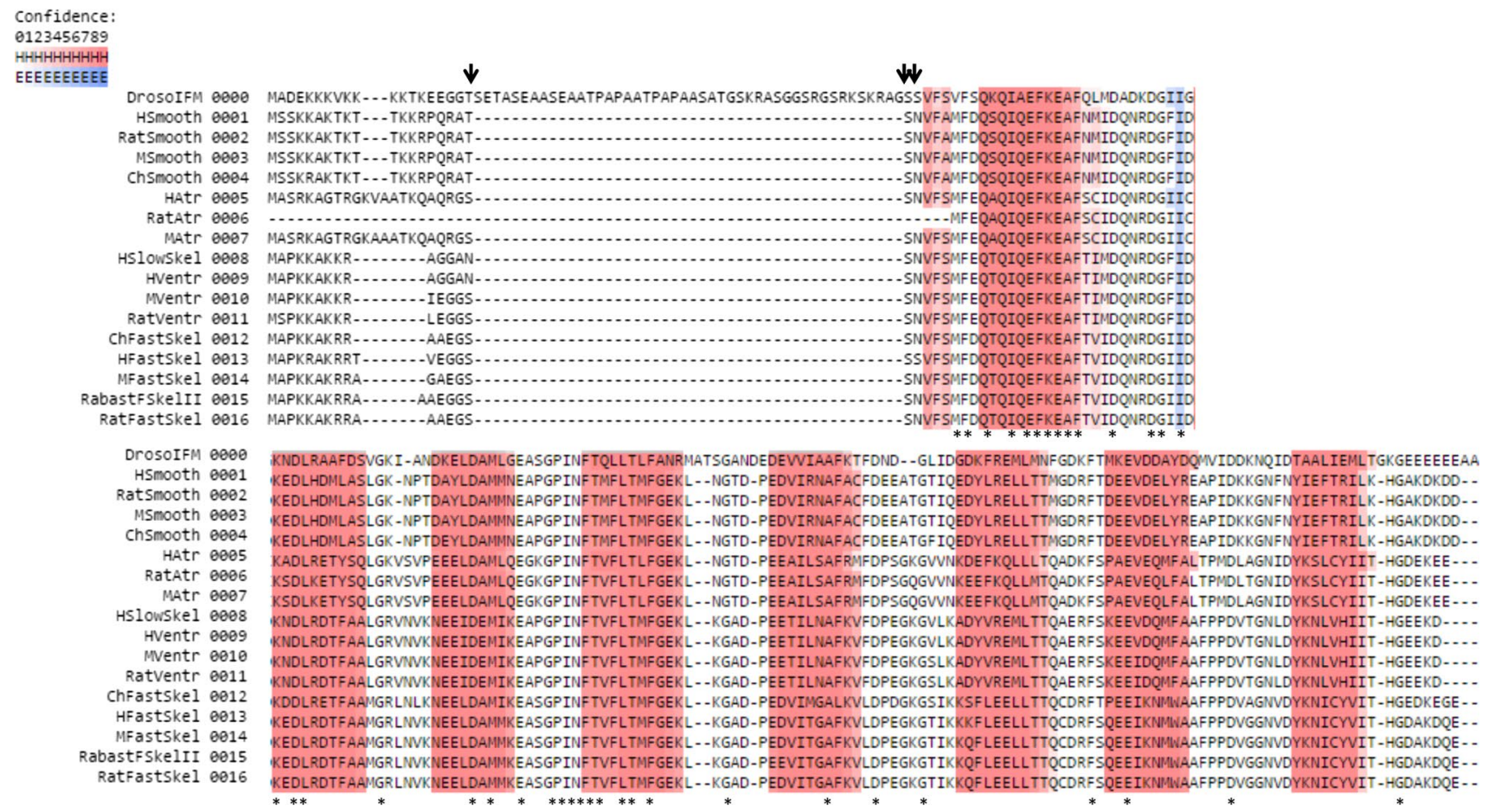

Fig. 2 Multiple sequence alignment (MSA) of different RLC isoforms from different laboratory model organisms and humans showing eight conserved predicted helices (red) forming part of the conserved four EF-hand secondary structure. The helix-loop prediction was performed in the Ali2D Bioinformatics toolkit of the Max Plank Institute of Developmental Biology (http://toolkit.tuebingen.mpg.de/ ali2d). The degree of confidence in prediction secondary structure is color coded in shades of increasing color intensity indicating increasing prediction confidence (for helix $(\mathrm{H})$ : white to dark red, for loops (E): white to dark blue). The black arrows indicate the conserved sites of physiologically relevant phosphorylation sites of RLC across species and tissues. The asterisks $\left(^{*}\right)$ indicate conserved residues across the sequences in the MSA. Sequences were retrieved from NCBI. Abbreviations used for biological sources of RLC sequences with their respective gene names and NCBI protein accession numbers are as follows: DrosoIFM (Drosophila indirect flight muscle,

ventricular RLC), where fast and slow describe the physiological behavior of different muscle groups. These three isoforms are encoded by different genes in the human chromosome 16, but with a high degree of sequence homology (Szczesna 2003).

In human heart, there are two different RLC isoforms expressed from separate genes, namely the atrial isoform (MYL2a) (NCBI Accession \# M94547) encoded from a gene in chromosome 7 and the ventricular isoform (MYL2v) (NCBI Accession \# P10916) encoded from a gene in chromosome 12, with the ventricular ones expressed in both ventricular myocardium and slow twitch skeletal muscle (MYL2f) (Kubalak et al. 1994; Price et al. 1980; Sarkar et al. 1971; Seidman and Seidman 1998).
MLC2, P18432.2), HSmooth (human smooth muscle, MYL12B, O14950.2), RatSmooth (rat smooth muscle, MYL12B, P18666.3), MSmooth (Mouse smooth muscle, MYL12B, Q3THE2.2), ChSmooth (chicken smooth muscle, MYL12A, P24032.2), HAtr (human atrial muscle, MYL7, Q01449.1), RatAtr (rat atrial muscle, MYL7, NP_001099487.1), MAtr (mouse atrial muscle, MYL7, Q9QVP4.1), HSlowSkel (human slow skeletal muscle, same as human ventricular), HVentr (human ventricular muscle, MYL2, P10916.3), MVentr (mouse ventricular muscle, MYL2, P51667.3), RatVentr (rat ventricular muscle, MYL2, P08733.2), ChFastSkel (chicken fast skeletal muscle, MYLPF, P02609.2), HFastSkel (human fast skeletal muscle, MYLPF, Q96A32.1), MFastSkel (mouse fast skeletal muscle, $M Y L P F$, P97457.3) RabastFSkelII (rabbit fast skeletal type II muscle, $M Y L P F$, P02608.3), RatFastSkel (rat fast skeletal muscle, MYLPF, $\mathrm{P} 04466.2)$

\section{Phosphorylation sites}

\section{Mammalian skeletal muscle}

Vertebrate skeletal muscle RLC is phosphorylated at two serine (Ser) residues, Ser14 and Ser15 (Fig. 2), by a skeletal muscle-specific $\mathrm{Ca}^{2+} /$ calmodulin-dependent myosin light-chain kinase (skMLCK) (Blumenthal and Stull 1980). The specific roles of the two neighboring RLC phosphorylation sites are unknown, but RLC phosphorylation at either site has a profound effect on force potentiation (isometric twitch tension potentiation) in fast, but not in slow, skeletal muscle (Moore and Stull 1984). Tarantula muscle has very thick myosin filaments, and their structure has been well studied by electron microscopy. It has been found that RLC 


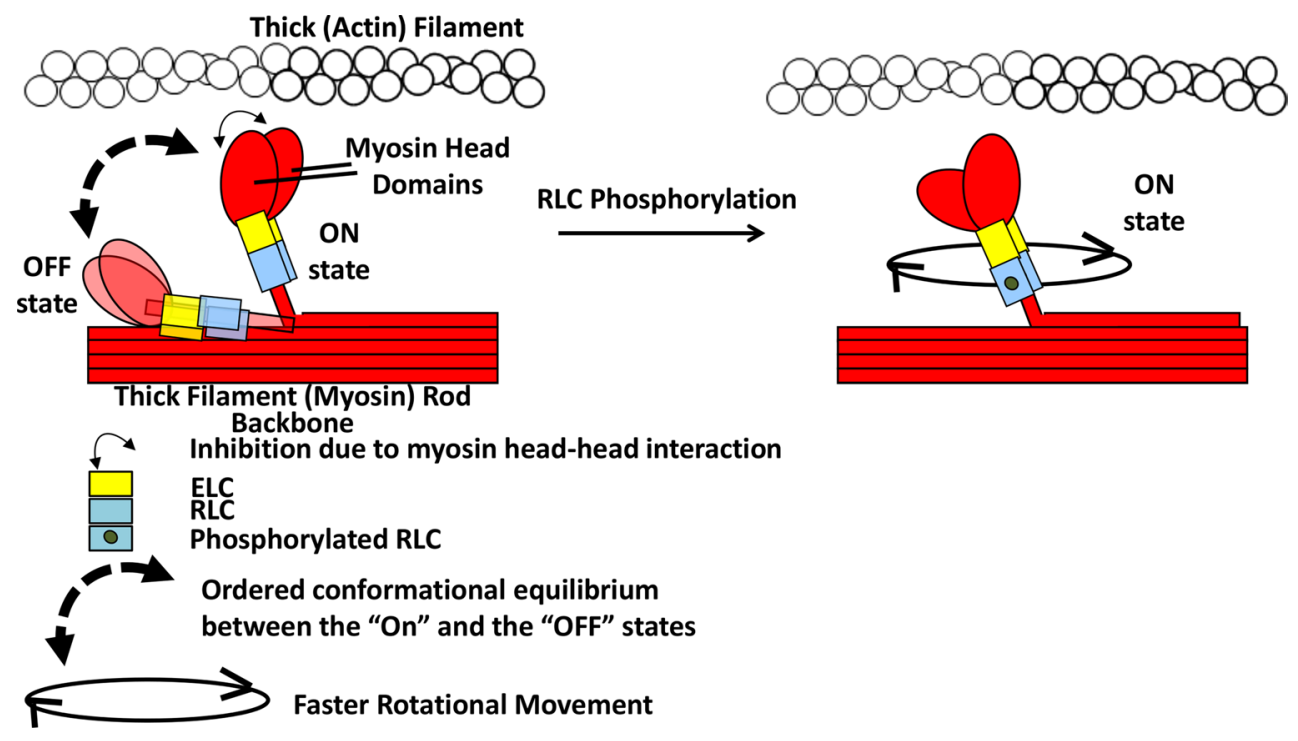

Fig. 3 Graphical representation of the effect of RLC phosphorylation on myosin head and lever arm arrangement. (Figure modified from Fig. 6c of Farman et al. 2009) Model based on skeletal muscle (Duggal et al. 2014; Midde et al. 2013) and cardiac muscle (Kampourakis and Irving 2015). In this model, without RLC phosphorylation, the myosin S1 and RLC regions are in conformational equilibrium between lying/binding to the thick filament backbone surface (OFF state) and moving away towards thin filament (ON state) controlled by the RLC and the thick filament surface. This equilibrium is shifted towards the ON state upon RLC phosphorylation, possibly due to weakened electrostatic interaction between the added phosphate and

phosphorylation changes the orientation of the myosin head on the thick filament backbone and is the contractile basis of force potentiation in striated muscles. It was found that force potentiation occurs by sequential and cooperative phosphorylation of two RLC sites in tarantula thick filament: first Ser35 by Protein Kinase C (PKC) and then Ser45 by Myosin Light Chain Kinase (MLCK) (EspinozaFonseca et al. 2015). This is further validated by molecular dynamic simulations showing that the diphosphorylation of both tarantula smooth and striated muscle stiffens the $\mathrm{N}$-terminal extension of RLC (region where phosphorylation occurs) so as to prevent its docking back towards the myosin S1 region, and in this way helps the free myosin head with Ser35 phosphorylation to remain away from thick filament backbone and available for actin binding (Alamo et al. 2015). It must, however, be borne in mind that tarantula thick filament may function very differently from vertebrate thick filaments. However, electron microscopic analyses of rabbit skeletal muscle showed that RLC phosphorylation has a major role in structural transitions, and modifies the mobility and disorder of the myosin head and myosin head crown/helical arrangement in the thick filament backbone resulting in force potentiation (Levine et al. 1996). RLC phosphorylation-induced force potentiation is enhanced in both disease (muscular dystrophy) and aging, negatively charged thick filament surface. The entire thick filament arrangement of myosin heads and other sarcomeric proteins (MyBPC, Troponin complex etc.) are not shown for simplicity. Not drawn to scale. (Notes: The ON and OFF states mentioned here are not related to the activation/deactivation with calcium binding/unbinding to Troponin C. The OFF-state myosin heads without RLC phosphorylation is drawn here lying on the thick filament backbone in the same direction as in the ON state, but it is possible that the OFF-state heads may fold on the opposite direction interacting with the thick filament backbone as drawn previously in Fig. 5 of Kampourakis and Irving 2015)

both of which affect neuro-muscular coupling (Smith et al. 2010). In these disorders, RLC phosphorylation may be a compensatory mechanism enhancing force potentiation. These effects and their physiological relevance may stem from RLC phosphorylation-induced movement of myosin heads away from the thick filament backbone towards the thin filament target zones facilitating contraction (see Fig. 3).

\section{Mammalian cardiac muscle}

In striated cardiac muscle from mouse or rat, RLC exists in three states: unphosphorylated, singly phosphorylated at serine 14 or 15 , and doubly phosphorylated at serine 14 and 15 . These sites are mostly phosphorylated by a cardiacspecific MLCK (cMLCK), and partly by zipper-interacting kinases (ZIP Kinase). While mouse and rat possesses phosphorylatable sites at both Ser14 and Ser15, human cardiac RLC (cRLC) has only one single phosphorylatable site at Ser15 (Fig. 2) (Lyon et al. 2009; Scruggs et al. 2010). Interestingly, human cRLC contains asparagine (Asn) instead of Ser14. Asn14 can be deamidated to aspartic acid (Pasparakis et al. 2010), chemically mimicking the negatively charged state of a phosphorylated serine, although there is no evidence that Asn14 is indeed deamidated 
physiologically. Therefore, human cRLC may exist in three distinct charged species in vivo: one unphosphorylated, one singly phosphorylated, and one phosphorylated/deamidated mimicking a doubly phosphorylated state (Scruggs et al. 2010). Moreover, isoform compositions expose differences between species. For example, human cRLC has two distinct charged isovariants with identical molecular weights, with one being more highly expressed and highly phosphorylated (Morano 1992; van Der Velden et al. 2001). Moreover, in non-failing human heart, the $\alpha$-MHC content comprise as much as $10 \%$ of the total MHC in cardiac sarcomeres (Miyata et al. 2000). This indicates that the isoenzymes in human cardiac muscle are not only created by the two different isovariants of RLC, but different MHC composition of the adult human left ventricle. In contrast, rat has one ventricular RLC isoform but the three isoenzymes are formed as mixtures of $\alpha$ and $\beta$ MHC (Kumar et al. 1986). Phosphorylation of RLC enhances the affinity of cross-bridges for action, or the rate of cross-bridge entry into the force generating states by moving cross-bridges closer to the thin filament (Colson et al. 2010). Physiologically, RLC phosphorylation may enhance the calcium sensitivity of cardiac myofilaments (Morano et al. 1985). Chris Toepfer sees an effect of phosphorylation in rat cardiac trabeculae at saturating calcium, so the effect cannot be fully attributed to enhancement of calcium sensitivity (Toepfer et al. 2013). Engineered in vivo mutations highlight the role of Ser14 and Ser15 phosphorylation (Ding et al. 2010; Sanbe et al. 1999). Phosphorylation of cRLC at both sites is required for normal cardiac ejection dynamics at baseline and also following $\beta 1$-adrenergic stimulation. Genetic engineering of the phosphorylation sites showed that Ser15 of cRLC is specifically phosphorylated by cMLCK (Kampourakis and Irving 2015), confirming that Ser15 is a physiologically relevant site.

\section{Mammalian smooth muscle}

In contrast to striated muscle, smooth muscle is activated by RLC phosphorylation at Ser19 of RLC. Both Thr18 and Ser19 are phosphorylated by smooth muscle specific myosin light chain kinase (smMLCK) in the presence of calcium and calmodulin (Pearson et al. 1984). Smooth muscle activation is, however, more complex than merely being turned on by phosphorylation of RLC and turned off by dephosphorylation. Smooth muscle force generation is maintained over long periods of time even though the extent of RLC phosphorylation declines over time (Driska et al. 1981). In vitro, smooth muscle RLC can be simultaneously phosphorylated at Thr18 position along with Ser19 by integrin-linked kinases and zipper-interacting kinases (ZIPK) (Ihara and MacDonald 2007; Wilson et al. 2005). Di-phosphorylation may occur in diseases of smooth muscle (Walsh 2011). Compared with mono-phosphorylation exclusively at Ser19, di-phosphorylation at both Ser19 and Thr18 slows relaxation of arterial smooth muscle by reducing the rate of dephosphorylation of the RLC (Sutherland and Walsh 2012). Using $\mathrm{Mn}^{2+}$-phos-tag gel electrophoresis technology for detecting phosphorylated variants of proteins, Aguilar et al. showed three differentially charged species of RLC in cultured uterine smooth muscle myocyte: unphosphorylated, singly and doubly phosphorylated (Aguilar et al. 2011). In spite of finding di-phosphorylated RLC in smooth muscle, mono-phosphorylated RLC at Ser19 by $\mathrm{Ca}^{2+} /$ calmodulin-dependent smMLCK predominates physiologically in adult smooth muscle tissues. In vitro, other phosphorylatable sites of RLC in smooth muscle are found. Calcium-activated phospholipiddependent protein kinase C (PKC) phosphorylates Ser1, Ser2, and Thr9 of smRLC, which reverses the increase in ATPase activity associated with smMLCK phosphorylation at Ser19 (Bengur et al. 1987; Ikebe et al. 1987).

\section{What do we know about the role of RLC phosphorylation?}

\section{Skeletal muscle}

Unlike in smooth muscle, RLC phosphorylation does not act as an activation switch but modulates striated muscle contraction. However, as in smooth muscle, RLC phosphorylation in skeletal muscle may also contribute to the release of the inhibition due to head-head and head-thick filament backbone interactions, facilitating binding with actin (Craig et al. 1987; Zhao et al. 2009). However, this role is not well understood. RLC phosphorylation enhances actomyosin interactions to accelerate myosin ATPase kinetics and force generation following calcium activation in skeletal muscle (Sweeney and Stull 1990). This is supported by structural studies which show that phosphorylation promotes the movement of the myosin heads away from the thick filament backbone resulting in the rotation of the cross-bridge/lever arm (Fig. 3) (Irving et al. 2000; Ushakov et al. 2011). In skeletal muscle, RLC phosphorylation may affect stiffness of the lever arm under isometric conditions and may be bringing the cross-bridges closer to the thin filament, without an effect on isometric tension generation. However, in non-isometric conditions, in vitro motility assays showed that actin filament gliding slows down upon RLC phosphorylation due to an increase in the myosin duty cycle (Greenberg et al. 2009). However, the structure of the myosin molecule or filament bound to a glass substrate as used in gliding assays may be substantially different from that encountered in muscle, which may result in different effects of phosphorylation in these two types of experiments. 


\section{Effect of RLC phosphorylation on actomyosin ATPase}

Myosin ATPase activity, in the absence of actin, is not affected by RLC phosphorylation (Persechini and Stull 1984). In fibers, phosphorylation of RLC enhances $\mathrm{Ca}^{2+}$ sensitivity of force development, but only slightly accelerated ATPase activity in skeletal muscle with low statistical significance in both reconstituted myosins and in permeabilized muscle fibers (Szczesna et al. 2002).

\section{Effect of RLC phosphorylation on force development and shortening}

Using rabbit psoas muscle fibers, it was found that RLC phosphorylation slowed muscle shortening velocity by $\sim 40 \%$ under physiological fatigue condition (such as $30{ }^{\circ} \mathrm{C}$, low $\mathrm{pH}$, and increased Pi concentration) of muscle (Karatzaferi et al. 2008), independent of myosin and in both relatively lower and higher temperatures. It has been proposed that at higher temperature in fatigued muscle with phosphorylated RLC, the myosin heads bind to the thick filament backbone, forming ordered arrays. This binding results in the myosin heads being further away from the thin filament binding sites upon $\mathrm{Ca}^{2+}$ activation, and increasing the fraction of myosin heads in non-force generating states during extreme fatigue conditions. Albeit, it is not known if inhibition of shortening velocity during fatigue is due to the direct role of RLC phosphorylation on nucleotide binding to myosin motor domain or not.

Interestingly, recently it was found that in a skeletal myosin light chain kinase knock-out (skMLCK-/-) mouse, the extensor digitorum longus (EDL) muscle exhibits no post-tetanic force potentiation after potentiating stimuli compared to that in wild-type control mice (Gittings et al. 2016). This observation highlights the link between RLC phosphorylation in force potentiation as without skMLCK, the majority of skRLC would remain non-phosphorylated.

\section{Cardiac muscle modulation by RLC phosphorylation}

The proportion of cardiomyocytes with well-organized sarcomeric structure increased in vitro in cells containing phosphorylated RLC compared to unphosphorylated cells in rat and zebra fish (Aoki et al. 2000; Seguchi et al. 2007). This indicated that RLC phosphorylation is involved during the development of cardiac sarcomeres. Some studies do not show a role for RLC phosphorylation; for example, it was shown that cardiac performance can be increased without increasing RLC phosphorylation in mice (Chang et al. 2013). Increased performance may be achieved by activating other signaling pathways such as CaMKII and with the help of neuregulin. However, RLC phosphorylation facilitates force production by increasing maximal isometric tension, calcium sensitivity of force, and the rate of force redevelopment at intermediate and saturating calcium activation levels (Olsson et al. 2004; Szczesna et al. 2002). Overall, RLC phosphorylation facilitates actomyosin interaction, most likely accelerates actomyosin kinetics, and enhances power output in cardiac muscle. These functional enhancements may promote sarcomeric organization during development. X-ray diffraction experiments on cardiac trabeculae with in situ RLC phosphorylation suggests a movement of the myosin head towards the thin filament upon phosphorylation (Colson et al. 2010), which might increase the probability of acto-myosin cross-bridge formation (Scruggs and Solaro 2011).

Some of the familial hypertrophic cardiomyopathy (FHC) mutations known in human cardiac RLC are found in the region of the Ser15 phosphorylation site, affect RLC phosphorylation and have a physiological effect (Szczesna et al. 2001). In Szczesna et al.'s report, of particular relevance, was the decrease in RLC phosphorylation in the A13T (site close to Ser15 site) and R58Q (site far from Ser 15 site) mutations causing abnormal $\alpha$-helical content and reduced $\mathrm{Ca}^{2+}$-binding properties of RLC, which were compensated upon subsequent phosphorylation (Szczesna et al. 2001, 2002). This indicates that RLC phosphorylation may be a key compensatory mechanism to attenuate the physiological consequences of FHC mutations in the heart. Toepfer et al. found that enrichment of RLC phosphorylation enhances force and power output in rat cardiac trabecular muscle (Toepfer et al. 2013). This study also shows that in both rats and humans, RLC phosphorylation increases with the severity of heart failure. This may support the view that RLC phosphorylation is a compensatory mechanism in cardiac disease. During the power stroke, the cross-bridge converts the torque generated in the myosin monomer into a linear displacement of the filaments with respect to each other (Burghardt and Sikkink 2013). Therefore, the possible immediate effect of RLC phosphorylation could be the movement of the myosin motor to facilitate inter-filament interactions, transient cross-bridge formation and detachment, and muscle contraction. Stelzer et al. incorporated MLCK to increase RLC phosphorylation in a MLCK knock-down background in permeabilized murine myocardium and found increases in the amplitude and rate of force development during stretch, i.e., enhancement of the stretch activation response. This further indicates that RLC phosphorylation increases force and power output in vivo, at least in the murine myocardium, by possibly increasing the rate of acto-myosin cross-bridge recruitment. Further work is required to understand the role of RLC phosphorylation on actomyosin kinetics, on stretch-activation, and on the behavior of the whole heart. 
The phosphorylation state of other myofibrillar proteins in both thick and thin filaments, namely that of myosin binding protein C (MyBP-C) and troponin I (TnI), are also affected by in vivo mutations of cRLC phosphorylation sites (Scruggs et al. 2009). There is evidence that MyBP-C binds to the myosin S2 region and RLC (Kampourakis and Irving 2015; Ratti et al. 2011). This indicates that cRLC phosphorylation events are linked to phosphorylation of other sarcomeric proteins. Signaling pathways may not control the phosphorylation of single proteins: the physiological response to stimuli may be a balanced increase in phosphorylation of a number of target sites.

In the heart, the overall pattern of contraction depends on a spatial gradient of RLC phosphorylation that is closely related to cardiac torsion (Davis et al. 2002), the consequence of which is an increased ejection fraction and cardiac stretch activation response (Davis et al. 2001). It was proposed that this variation of RLC phosphorylation ranging from high levels in the epicardium to low levels in the endocardium could be due to phosphatase activity that may be higher in the inner layers of the myocardium. This, in turn, could possibly be a mechanism to reduce inner wall stress of the heart during systole (Cohen 2002; Rajashree et al. 2005). These studies suggest that the gradient of RLC phosphorylation supports the cardiac torsional movement and thus facilitates overall cardiac contraction. Interestingly, a recent study in rat heart shows that an increase in RLC phosphorylation slows down the rates of both crossbridge MgADP release and MgATP binding at $1.9-\mu \mathrm{m}$ sarcomere length, whereas only slows down cross-bridge MgATP binding at 2.2- $\mu \mathrm{m}$ sarcomere length with no effects on the rate of MgADP release (Pulcastro et al. 2016). This indicates that RLC phosphorylation has a differential role on cross-bridge kinetics depending on sarcomere length. This connects to and adds to the concept that RLC phosphorylation can vary across the heart from left to right ventricles and between fibers based on the local extent of mechanical loading and stretching to optimize normal cardiac torsional movement and overall contraction.

Recently, cardiac RLC phosphorylation was found to directly control the movement of the myosin-RLC region and myosin S1-region from a position more parallel and towards the thick filament backbone to a position more perpendicular and away from the thick filament backbone, facilitating cross-bridge formation, enhancing myosin kinetics, and force production (Kampourakis and Irving 2015). This suggests that RLC phosphorylation is a major modulator in releasing the myosin head-thick filament backbone interaction and inducing movement away from the backbone towards the thin filament. This mechanism agrees well with the hypothesis proposed for super-relaxed state (SRX) of myosin head in cardiac muscle (Hooijman et al. 2011) and for skeletal muscle (Stewart et al. 2010).
This ordered "blocked" (lying on thick filament) arrangement of the myosin heads across the thick filament surface in SRX is modulated by phosphorylation of RLC and MyBP-C (Kensler et al. 2011; Levine et al. 1996). Supporting this, de-phosphorylation of RLC stabilizes the ordered array of myosin heads bound or lying on the thick filament surface away from thin filament, decreasing cardiac power output during SRX (Dias et al. 2006; Scruggs et al. 2009).

\section{Smooth muscle: the role of RLC phosphorylation}

The role of RLC and its phosphorylation is better characterized in smooth muscle and non-muscle cells than in striated muscle. RLC phosphorylation triggers smooth muscle contraction, unlike in striated muscle. Phosphorylation of RLC in both smooth muscle and non-muscle myosins modulates the tension and activates the myosin ATPase (Bresnick 1999). The mechanism by which RLC phosphorylation induces the release of the two-head interactions, a feature specific to smooth muscle to activate the myosin motor is not clearly known. According to molecular dynamics (MD) simulation along with electron paramagnetic resonance (EPR) and fluorescence resonance energy transfer (FRET) experiments, the smooth muscle RLC (smRLC) phosphorylation domain (PD) shifts to a more ordered state from a disordered conformation upon phosphorylation at Ser19 (Espinoza-Fonseca et al. 2007). The overall tertiary structure of the RLC and the light chain domain region of the myosin S1 undergo a shift from a closed or ordered state to a more open or disordered state of conformation (Colson et al. 2012; Taylor et al. 2014) upon phosphorylation. This conformational change could facilitate the release of the myosin S1, activating its ATPase activity. In addition, in non-muscle cells as well, RLC phosphorylation is required for normal cell division processes and cytokinesis. Both the phosphorylation sites and the pattern of phosphorylation characterize striated and smooth muscle RLC phosphorylation and highlight the fact that the consequence of RLC phosphorylation is quite different in these two muscle classes.

\section{Possible mechanism of RLC phosphorylation in striated muscle}

The structural and functional role of RLC phosphorylation has also been investigated in genetic models such as Drosophila. X-ray diffraction on live flies and active muscle fibers shows that RLC phosphorylation orients the myosin motor domain towards the thin filament target to enhance actin binding compared to non-phosphorylated RLC (Farman et al. 2009). Cross-bridges without RLC phosphorylation are more ordered in relaxed mammalian skeletal muscle since they lie closer to the thick filament 
core (Cooke 2011). However, during contraction, skeletal muscle cross-bridges with phosphorylated RLC rotate at higher azimuthal angles and are less ordered compared to those without RLC phosphorylation (Midde et al. 2013). This is in contrast to what is found in insect flight muscle (Farman et al. 2009) where RLC phosphorylation reduces the azimuthal movement of the myosin head, enabling a better orientation towards actin targets. Moreover, in active isometric condition, Midde et al. (2013) found that rotational movement of the myosin lever arm (myosin S1's RLC region) is faster with phosphorylated RLC than with dephosphorylated RLC even with the myosin duty cycle and isometric tension remaining the same in both cases. Upon RLC phosphorylation, the myosin S1 head domain and the S1 RLC region are more disordered compared to non-phosphorylated RLC. However, Duggal et al. reported that in skeletal muscle, RLC phosphorylation has a minimal effect on the ordering of the myosin S1 head domains or their distribution (Duggal et al. 2014). These contrasting results highlight the need for a better understanding of the role of RLC phosphorylation and that RLC phosphorylation may have different consequence in different tissues or animal systems. In summary, RLC phosphorylation causes disordering of the myosin head domain but not the RLCregion of S1. The S1 RLC region may remain ordered due to its interaction with the thick filament backbone. Phosphorylation may shift this structural equilibrium possibly due to the electrostatic repulsion of phosphate with the negatively charged surface of the thick filament backbone. Alternatively, whether the effect of RLC phosphorylation is to disorder the S1's RLC-region and S1's myosin head domain or to just shift the equilibrium of the interaction between S1's RLC region and thick filament backbone surface to an "ON" state (not referring to calcium activation) may depend on the type of muscle skeletal (Midde et al. 2013), or cardiac (Kampourakis and Irving 2015). In the ON-state, it is proposed that due to RLC phosphorylation, the myosin head and S1-RLC region axis is more perpendicular to the thick filament backbone, whereas without phosphorylation in the OFF-state, it is more parallel to the thick filament axis (Kampourakis and Irving 2015) (see Fig. 3). RLC phosphorylation releases the inhibition (OFF state) caused by interaction between myosin S1 head-head and S1's head domain/S1 RLC region with the thick filament backbone interaction to facilitate head and lever arm movement away from the backbone and towards the thin filament, based on evidence from smooth muscle (Baumann et al. 2012; Rosenfeld et al. 1998), permeabilized mammalian cardiac muscle studies (Colson et al. 2010), and Drosophila indirect flight muscle (Farman et al. 2009). A summary of the known physiological functions of RLC phosphorylation in striated muscle is shown in Table 1.

\section{Biomedical significance of RLC phosphorylation}

As RLC phosphorylation modulates muscle cell behavior, defects in RLC phosphorylation result in dysfunction and disease. Mutations in either ELC or RLC are associated with myopathies in human heart and skeletal muscle (Poetter et al. 1996).

In skeletal muscle, RLC phosphorylation plays a role in post-activation potentiation, which is induced by a sudden and intense voluntary contractile activity like jumping or sprinting etc. (Baudry and Duchateau 2007; Sale 2002). The role of RLC phosphorylation in post-activation potentiation may stimulate research to improve human performance in stretch (extrinsic) and endurance exercise. RLC phosphorylation and increased recruitment of motor units have been proposed as the mechanism of post-activation potentiation that leads to increased peak force and rate of force development during twitch contractions. Increasing RLC phosphorylation may be an effective strategy for improving skeletal muscle performance in athletes as well as in the aging population.

In the heart, genetic knock-out mice were used to understand the role of the ventricular and atrial isoforms of RLC, MYL2v, and MYL2a, respectively, in cardiac contractile function (Sheikh et al. 2015). The mutations of RLC are associated with the mid left ventricular chamber hypertrophic cardiomyopathy (HCM) phenotype. Although it is not entirely clear how these abnormal phenotypes are driven by changes at the molecular level, RLC mutants linked to these diseases are known to modify the cardiac myosin lever arm (Hernandez et al. 2007). Burghardt et al. studied the relationship between different disease-related mutants in RLC and heart diseases using photo-activatable GFP-tagged RLC (RLCPAGFP), a novel technique that permits single-molecule detection (Burghardt and Sikkink 2013). They found that the HCM-linked E134A mutation of RLC, a charged residue probably participating in the binding of human cardiac RLC to the myosin lever arm, affects actin binding during contraction evidenced by a decrease in isometric tension.

Cardiac hypertrophy is the heart's response to a variety of extrinsic and intrinsic stimuli that impose increased biomechanical stress (Frey and Olson 2003). Increased cardiac RLC phosphorylation may limit cardiac hypertrophy by contributing to enhancement of contractile performance and efficiency. This may result from facilitating actomyosin interactions and enhancing contractility to adapt to cardiac stress (Huang et al. 2008; Muthu et al. 2012). Additionally, pressure overload leads to severe heart failure in mice with dephosphorylated cardiac RLC but less so in mice with over-phosphorylated cardiac RLC (Warren et al. 2012). Thus, strategies to control RLC phosphorylation may benefit heart function in disease. 


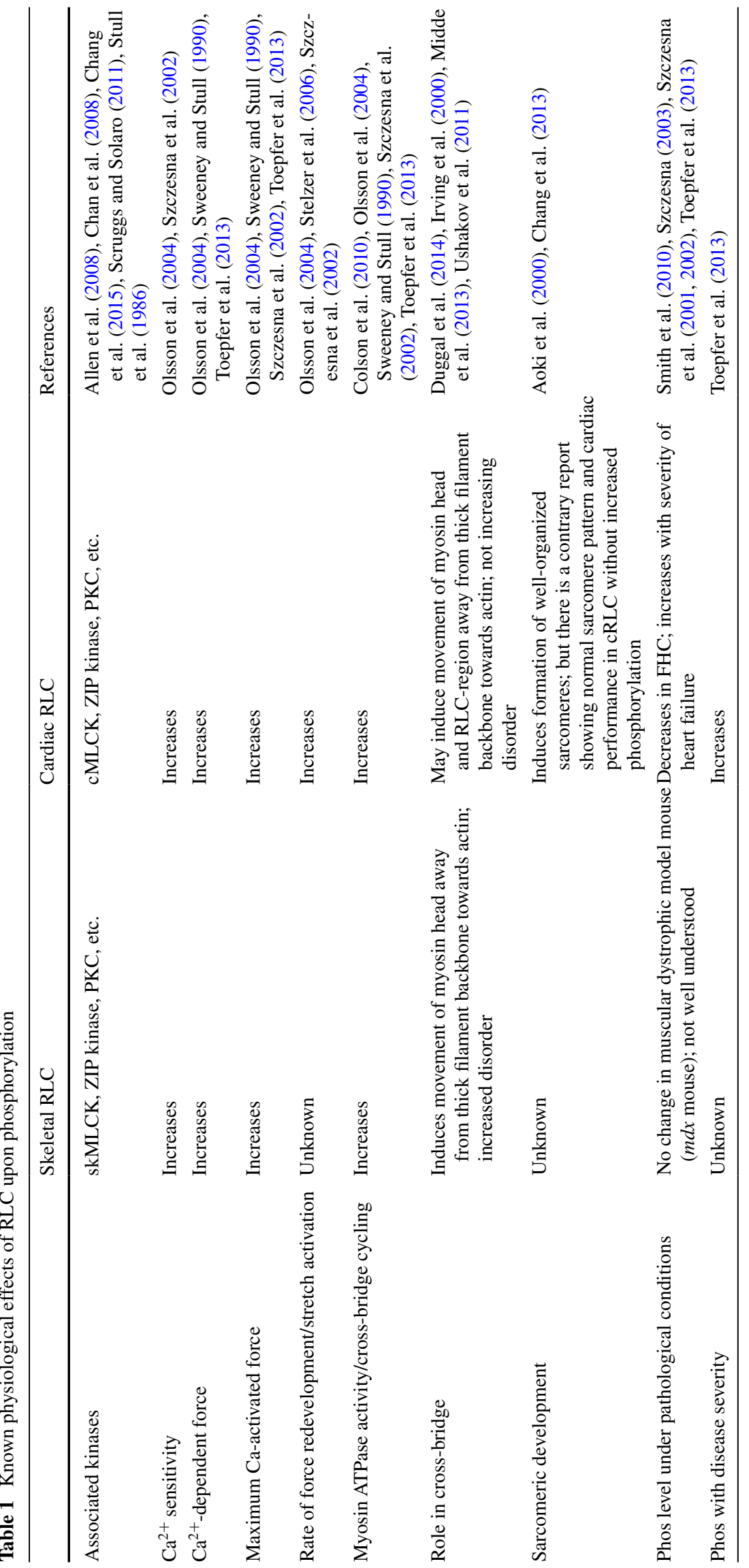


In addition, measurement of the extent of RLC phosphorylation has potential as a diagnostic tool for human heart disease phenotypes. A recent study tested cardiac left ventricular (LV) biopsy samples from patients either with LV hypertrophy and preserved systolic function or with LV dilation and reduced ejection fraction (Walker et al. 2013). In patients with preserved systolic function, cardiac RLC phosphorylation was unchanged relative to a control group of patients with normal LV function, whereas in patients with LV dilation and reduced ejection fraction, cardiac RLC phosphorylation was increased. A role for phosphorylation of RLC in various cellular functions and diseases is evident. Thus, understanding the stage-specific changes in phosphorylation of RLC in progressive heart diseases, either heart failure or cardiomyopathic conditions, may provide important and early diagnostic and therapeutic information.

In the paragraphs that follow, we will present a summary of existing methods for measuring and modifying the extent of RLC phosphorylation and discuss their merits and problems.

\section{Techniques to phosphorylate or dephosphorylate RLC}

Techniques to phosphorylate or dephosphorylate RLC include computational simulation, modeling, and experimental methods. Mathematical simulations describe the phosphorylation and de-phosphorylation dynamics of RLC by modifying biochemical and enzymatic parameters (Kaneko-Kawano et al. 2012). However, simulations need validating by experimental data. Here, we emphasize experimental techniques for: (1) increasing phosphorylation of RLC, and (2) techniques to de-phosphorylate RLC, and (3) the measurement of phosphorylation levels. The merits and limitations of the experimental tools will be discussed, divided into in vivo and in vitro methods.

\section{In vivo modifications}

Much of our knowledge about native myosin light-chain functions comes from studies in muscle of animal models such as mouse, rat, rabbit, swine, zebrafish, and Drosophila (Kaneko-Kawano et al. 2012). Several studies have measured the extent of native RLC phosphorylation in various tissues that seems to reflect variation in the phosphorylation extent between them. In quickly frozen biopsy samples of human heart, RLC phosphorylation varies between the atrial and the ventricular isoforms, with the two ventricular isoforms varying in the range of 0.26-0.39 mol Pi/mol RLC (Morano 1999). Toepfer et al.
(Toepfer et al. 2013) found a similar level of RLC phosphorylation ( $0.4 \mathrm{~mol} \mathrm{Pi} / \mathrm{mol} \mathrm{RLC})$ at the inner ventricular wall of the human myocardium. However, basal RLC phosphorylation values found in different studies differ (Peng et al. 2014; Sanbe et al. 1999; Scruggs and Solaro 2011). Heterogeneous levels of phosphorylation between different parts of the myocardium (Davis et al. 2001; Dias et al. 2006; Sheikh et al. 2012) add to the complication. For example, recently, the basal in vivo cRLC phosphorylation in the rodent heart is found to be even lower (<0.05 mol Pi/mol RLC) (Kampourakis and Irving 2015) than reported before $(\sim 0.4 \mathrm{~mol} \mathrm{Pi} / \mathrm{mol} \mathrm{RLC})$ (Toepfer et al. 2013). The difference could also be caused by handling such as rapid dephosphorylation during sample preparation. Previously, in case of rodent models, RLC phosphorylation level in the inner left ventricular wall of rats hearts is found to be higher than in human $(0.53 \mathrm{~mol} \mathrm{Pi} / \mathrm{mol}$ RLC) (Toepfer et al. 2013). However, normal RLC phosphorylation levels in swine left ventricular wall is similar to that in humans (Toepfer et al. 2013). In case of skeletal muscle, the extent of normal RLC phosphorylation is lower than in cardiac muscle, with the mouse fast twitch EDL muscles showing about 0.1-0.2 mol Pi/mol RLC, and the mouse slow twitch soleus muscle showing about 0.08-0.18 mol Pi/mol RLC (Ryder et al. 2007). Therefore, in vivo modification of RLC phosphorylation status may result in directly measurable physiological effects.

\section{Transgenic approaches: modulation by kinases}

Transgenic techniques are widely used for in vivo modification, most of which are used to lower the RLC phosphorylation level. For this purpose, modulation of MLCK expression is frequently used. Mammalian smooth, skeletal, and cardiac muscle MLCKs are encoded by MYLK1, MYLK2, and MYLK3 genes, respectively (Gallagher et al. 1991; Herring et al. 2000; Yin et al. 2006; Zhi et al. 2005). Ding et al. generated a transgenic mouse expressing the cMLCK hypomorphic allele $\left(c M L C K^{\text {neo/neo }}\right)$ by crossing $c M L C K^{+/ n e o}$ to each other in order to assess myosin RLC phosphorylation and cardiac performance in vivo (Ding et al. 2010). Two cMLCK-targeted embryonic stem cell clones were identified and injected into C57BL/6 blastocysts that were transferred to the uterus of pseudo pregnant females. The extent of RLC phosphorylation in ventricular and atrial tissues of $c M L C K^{+/ n e o}$ mice was less than $5 \%$, indicating successful dephosphorylation by modulating MLCK. In another in vivo study, skMLCK-deficient mice were generated by transferring MYLK2 knock down into C57BL/B6 blastocysts and implanting into pseudopregnant C57ICR females (Zhi et al. 2005). Loss of skMLCK reduced RLC phosphorylation in skeletal muscle by $95 \%$ but had no effect on cRLC phosphorylation. 
It has been shown in smooth muscle that when tamoxifen treatment is combined with transgenic specific promoter targeting and tamoxifen-activated Cre recombinase (a tyrosine recombinase enzyme derived from the P1 Bacteriophage), smMLCK expression is tissue-specifically abolished (Kuhbandner et al. 2000). This resulted in lower levels of RLC phosphorylation and consequent functional implications (He et al. 2008). A similar strategy using tamoxifen activated and tissue-specific knock-out of smMLCK in vivo created a transgenic mouse strain with very low levels of RLC phosphorylation in smooth muscle (Somlyo et al. 2004; Zhang et al. 2010). This transgenic strategy could be applied in striated muscle as well. Thus, targeting MLCK genetically or in combination with pharmacological intervention is effective for tissue-specific modulation of RLC phosphorylation. In vivo modification of MLCK is an effective technique for examining the function of RLC phosphorylation in specific muscle tissue systems.

\section{Transgenic approaches: P-element-mediated germline transformation}

In vivo transgenic approaches were utilized in Drosophila to understand the role of the conserved MLCK phosphorylation sites of RLC in the stretch activation response, which has features resembling the behavior of mammalian cardiac muscle (Dickinson et al. 1997; Farman et al. 2009; Miller et al. 2011; Tohtong et al. 1995). Transposon-element or P-element-mediated germ-line transformation was used for creating transgenic Drosophila strains expressing mutant RLC with alanine substitutions of MLCK phosphorylatable serines (Ser66 and Ser67 of Drosophila RLC: Fig. 2) (Farman et al. 2009). Analysis of the mechanical response of permeabilized Drosophila flight muscles to applied sinusoidal length changes suggested that MLCK phosphorylation of the two conserved serines are required for normal orientation of the myosin heads towards actin target zones. This, in turn, accelerated myosin kinetics, increasing the number of strongly bound cross-bridges and stretch-activated power output (Miller et al. 2011).

\section{Transgenic approaches: pseudo-phosphorylation}

Pseudo-phosphorylation is used both in vitro and in vivo. In this method, one or more amino acid residues are mutated to an acidic amino acid [aspartic acid (D) or glutamic acid (E)], which carries a negative charge that mimics the charged state of a phosphorylated residue. Based on the known cRLC crystal structure and on molecular dynamics (MD) simulations, the in vivo phosphorylatable site of Ser15 is proximal to the D166V (Aspartate166 $\rightarrow$ Valine) mutation site of cRLC known to cause familial hypertrophic cardiomyopathy (FHC). Muthu et al. created a S15D (phosphorylated Ser15) pseudophosphorylated mutation site in the cRLC protein carrying the D166V mutation (Muthu et al. 2014). They found that this in vitro strategy rescues the charged state of the aspartic acid (D166) site and the contractile function in vitro since the Ser15 and D166 sites are proximal. Recent in vivo research engineered pseudophosphorylated RLC mice by using S15DD166V mutation technique (Yuan et al. 2015) and found that pseudophosphorylated RLC in the hearts of HCM mice is sufficient to prevent the development of the pathological HCM phenotype. This method can also be used in other types of muscle. A similar strategy of combining MD simulations and pseudophosphorylation has also been utilized in smooth muscle RLC to understand the structural effect of the physiological phosphorylation of Ser19 and the neighboring Thr18 (see Fig. 2) of the smRLC (Espinoza-Fonseca et al. 2008). Therefore, combining in silico MD simulations and pseudophosphorylation is a powerful technique for understanding basic structure-function relationship and also the mechanistic basis of disease-causing mutations of RLC. Pseudophosphorylation not only improves systolic function but also avoids adverse effects resulting from the D166V RLC mutation (Granzier and de Tombe 2015). In such pseudophosphorylation, the phospho-mimic negative charge is constitutive, which means that in vivo, the heart cannot control the charged-state of RLC and dynamically respond to altered demands.

Recently, it was found that in the beating heart, cRLC is constitutively and stably phosphorylated at a level of $0.45 \mathrm{~mol} \mathrm{Pi} / \mathrm{mol}$ RLC due to a balance between cMLCK activity and MLCP (myosin light-chain phosphatase) activity (Chang et al. 2015). Thus, pseudophosphorylated RLC along with unphosphorylated RLC at in vivo ratios can be used for exchange into muscle fibers or myofibrils to test functional implication of RLC phosphorylation in normal and disease conditions, assuming that the $\mathrm{D}$ substitution is physiologically analogous to serine phosphorylation in vivo. The drawback of this $\mathrm{S} 15 \mathrm{D}$ mutation approach is that it will not easily be adapted to patients. A possible alternative is the manipulation of the activities of either cMLCK (increasing it) or cMLCP (lowering it) (Granzier and de Tombe 2015). The reason is that these enzymes are highly specific toward cRLC, and therefore the technique may be feasible without adversely affecting effects on other proteins (Kamm and Stull 2011).

\section{Direct phosphorylation}

In addition to transgenic methods, RLC can be directly phosphorylated in vivo. For example, the hypertrophic agonist angiotensin II (AngII) plays an important role in regulating vascular tone as well as in maintaining systemic blood 
pressure. Volatile anesthetics may inhibit AngII-induced vascular contraction via inhibiting RLC phosphorylation (Qi et al. 2009). Aoki et al. injected AngII and phenylephrine into the jugular vein of adult rats to promote phosphorylation of cRLC in the heart (Aoki et al. 2000). AngII and phenylephrine increased the basal level of phosphorylated RLC by 30 to $38 \%$ and by $45 \%$, respectively. The increased RLC phosphorylation is caused by activation of the $\mathrm{Ca}^{2+} /$ calmodulin pathway activation and subsequent MLCK activation. This method induces the formation of well-organized sarcomeres in the cardiomyocytes. In other studies, mice were treated with $\beta$-adrenergic agonists like Isoproterenol (Isoprenaline), which induces cardiac hypertrophy in wild-type mice and is associated with an increase in MYL2v phosphorylation in mice that lack cMLCK, by activating the ZIP Kinase (Ding et al. 2010). A recent study infused AngII type 1 receptor (AT1R) biased ligand, namely TRV120023, into DCM mice for $15 \mathrm{~min}$. The observed enhancement of cardiac contractility was associated with an increase in ventricular MYL2 phosphorylation activated by the $\beta$-arrestin downstream signaling pathway (Tarigopula et al. 2015). AT1R may prove to be a novel inotropic approach in familial DCM. Other inotropic agents such as pimobendan and levosimendan probably inhibit phosphodiesterase, which may limit their use in DCM (Kass and Solaro 2006; Nonaka et al. 2015). These studies suggest that hypertrophic stimuli act upstream of cRLC phosphorylation. These pharmacological stimuli can be used to understand the function of cRLC phosphorylation in disease processes. The phosphorylation level achieved exceeds the physiological levels and thus may not reflect an in vivo mechanism. However, lowering doses of hypertrophic agonists may achieve physiological levels of RLC phosphorylation. Agonist administration is invasive, so side effects need to be checked, such as compensatory over- or under-expression of other proteins and non-physiological phosphorylation of RLC or other proteins. RLC phosphorylation is manipulated directly with agonists but the effects are difficult to control. Additionally, a study used $15-\mathrm{Hz}$ tetanic stimulation in skMLCK knock-out mice, and found some RLC monophosphorylation (Zhi et al. 2005). However, it may be caused by redundancy between skMLCK and smMLCK, so this method is not widely used (Takashima 2009a).

Nevertheless, in vivo phosphorylation targets specific RLC isoforms, which allows exploration of phosphorylation effects in different muscle types under physiological conditions. Commonly used in vivo methods are summarized in Table 2.

\section{In vitro modification}

In vitro modification of RLC phosphorylation levels is relatively simple and gives high phosphorylation efficiency.

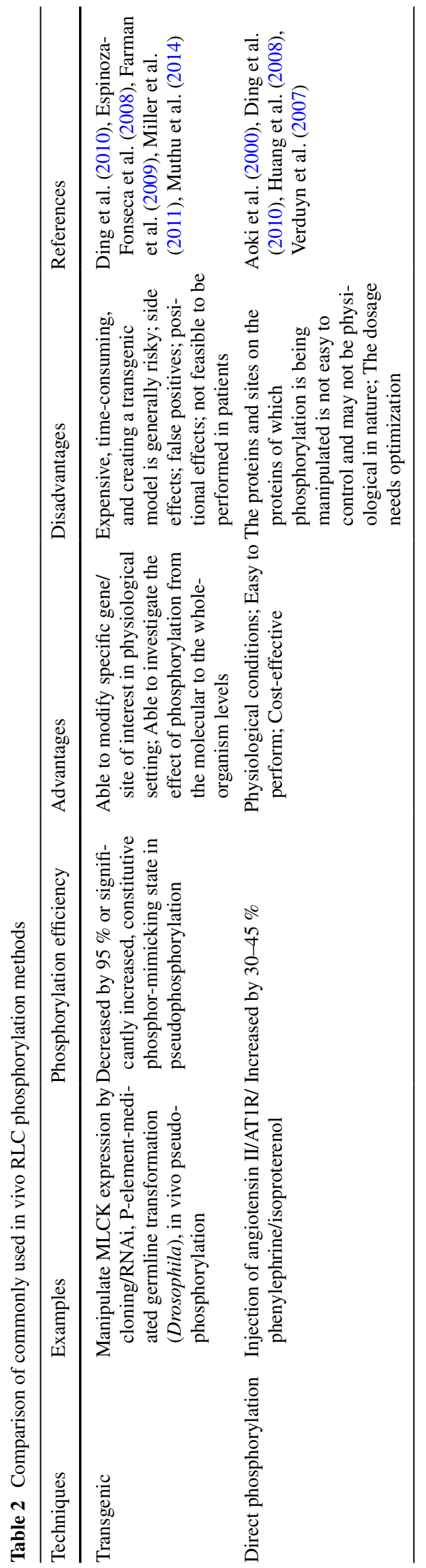


In vitro methods include enzymatic, genetic, chemical, biological approaches, and direct physico-chemical methods.

\section{Overview of kinase methods}

Kinases used for in vitro modification of the phosphorylation state include MLCK, PAK, and Rho-kinase. The MLCK family is a set of calmodulin-dependent protein kinases which readily phosphorylate different RLCs. Smooth muscle MLCK (smMLCK) is expressed in most tissue including smooth muscle, skeletal muscle, and cardiac muscle. smMLCK catalyzes $\mathrm{Ca}^{2+} /$ calmodulindependent phosphorylation of RLC in epithelial, endothelial, and other kinds of non-muscle cells. The smMLCK is sufficient for initiating smooth muscle contraction or actomyosin-dependent movement in non-muscle cells (Yu et al. 2010). Thus, the smooth muscle MLCK expressed by the MYLK gene is ubiquitous. In smooth muscle cells, the concentration of smMLCK and its substrate, RLC, is about $4 \mu \mathrm{mol} / \mathrm{l}$ and 30-40 $\mu \mathrm{mol} / \mathrm{l}$, respectively (Takashima 2009b). The skMLCK is a distinct kinase mainly found in skeletal muscle, particularly in fast-twitch fibers (Allen et al. 2008). Although it was reported in cardiac muscle, the amount is too low to maintain cardiac RLC phosphorylation (Davis et al. 2001) as demonstrated by knock-outs of skMLCK with no effect on cRLC phosphorylation (Zhi et al. 2005). The skMLCK is not selective, as it phosphorylates RLCs from smooth, skeletal, and cardiac muscles with similar maximal rate $\left(V_{\max }\right)$ and Michaelis constant $\left(K_{\mathrm{m}}\right)$ (Stull et al. 1986). Although skMLCK is activated by $\mathrm{Ca}^{2+}$ and the catalysis core recognizes the RLC binding site, the mechanism is different from that of smMLCK. Under steady-state conditions, skMLCK follows a rapidequilibrium random bi-bi reaction (two substrates converted to two products) whereas smMLCK proceeds by an ordered sequential mechanism in which Mg-ATP binds first, followed by the RLC substrate (Bowman et al. 1992). cMLCK is a kinase first found in 2008 and only present in vertebrate cardiac ventricular and atrial myocytes (Chan et al. 2008). The cMLCK has a catalytic core domain and regulatory segment that are conserved in skMLCK. However, there is uncertainty about whether the cMLCK kinase ability to phosphorylate RLC is $\mathrm{Ca}^{2+} /$ calmodulin dependent or not. In rat cardiomyocytes, cMLCK phosphorylates RLC without $\mathrm{Ca}^{2+} /$ calmodulin dependence in vitro (Chan et al. 2008). However, at around the same time, human cMLCK was found to be $\mathrm{Ca}^{2+} /$ calmodulin dependent in vitro (Seguchi et al. 2007). Recently though, it has been shown in rat trabeculae that cMLCK indeed phosphorylates cRLC in a $\mathrm{Ca}^{2+} / \mathrm{Calmodulin-dependent} \mathrm{manner} \mathrm{both}$ in vitro and in situ (Kampourakis and Irving 2015). The phosphorylation efficiency was about $100 \%(1 \mathrm{~mol} \mathrm{Pi} / \mathrm{mol}$ RLC) and the fact that in vivo multiple phosphorylated species of cRLC are present may be explained by the presence of different kinases for cRLC other than cMLCK in rodent heart (Chang et al. 2010; Jiang et al. 2014; Venema et al. 1993).

MLCKs have been used to phosphorylate RLC in muscles from various species such as rabbit, mouse, rat, and Drosophila (Stull et al. 2011). MLCK is available commercially. Alternatively, it can be recombinantly isolated and purified in the laboratory (Greenberg et al. 2009). Besides MLCK, other kinases such PAK are also widely used in RLC phosphorylation. A detail review will be given below.

\section{Phosphorylation and de-phosphorylation methodology targeting or using kinases}

In vitro phosphorylation of cRLC is simply achieved by incubating $0.5 \mu \mathrm{M}$ of MLCK with zipper-interacting kinase (ZIP kinase) dissolved in buffer (containing $\mathrm{CaCl}_{2}, \mathrm{MgCl}_{2}$, ATP, etc.) and incubated with 0.1-0.5 $\mu \mathrm{M}$ RLC for $0.5-2 \mathrm{~h}$ at $25-37^{\circ} \mathrm{C}$ or at $4{ }^{\circ} \mathrm{C}$ overnight. This method yields almost $100 \%$ cRLC phosphorylation, i.e., the cRLC species are phosphorylated at Ser15 position with almost $100 \%$ efficiency (Toepfer et al. 2013). A higher concentration of MLCK may result in diphosphorylation. The ZIP Kinase is added along with cMLCK in order to increase RLC phosphorylation to the required level, since ZIP Kinase directly phosphorylates cRLC independently of MLCK pathway (Chang et al. 2015).

Using purified cMLCK catalytic domain along with $\mathrm{Ca}^{2+} /$ calmodulin, ATP $\gamma \mathrm{S}$ thiophosphorylates Ser15 of cRLC that was labeled by bifunctional sulforhodamine (BSR). ATP $\gamma \mathrm{S}$ was used because thiophosphorylated proteins are relatively resistant to dephosphorylation by contaminating or endogenous protein phosphatases in the muscle tissue samples (Gratecos and Fischer 1974). In this study (Kampourakis and Irving 2015), at a cMLCK:cRLC ratio of $1: 500$ or $1: 200$, almost $100 \%$ of cRLC was monophosphorylated. Thiophosphorylated cRLC was then exchanged into demembranated muscle fibers to visualize the orientation of myosin S1's cRLC region in the actomyosin machinery using polarized fluorescence measurements in resting, active, and rigor conditions. Although, only about 10-30\% exchange of the BSR-labeled thiophosphorylated cRLC was achieved, this may closely mimic the basal in vivo level of phosphorylated cRLC (40-50 \%) in the contracting myocardium as was reported before (Herring and England 1986; Silver et al. 1986). Exchange and incorporation of BSR-labeled thiophosphorylated cRLC had minimal effect in overall protein composition of the permeabilized tissue, only lowering the total amount of few proteins. Significantly though, exchange of the BSRthiophosphorylated cRLC caused lowering of the amount of phosphorylated TnI and phosphorylated MyBP-C. 
Recombinantly expressed RLC is dephosphorylated with shrimp alkaline phosphatase in vitro (Toepfer et al. 2013). MLCK inhibitors such as $50 \mu \mathrm{M}$ of ML-9 and $400 \mu \mathrm{M}$ of nonapeptide rkkykyrrk-NH $\mathrm{N}_{2}$ (D-PIK) are also used to reduce RLC phosphorylation in vitro (Feighery et al. 2008). Mixing specific ratios of phosphorylated and de-phosphorylated RLC prior to light-chain exchange into permeabilized cells effectively provides control of the phosphorylation. For example, in vivo conditions of RLC phosphorylation without tampering with the phosphorylation level of other sarcomeric proteins are achieved. The approach takes advantage of the fact that RLC is readily exchangeable in permeabilized muscle cells (Borejdo et al. 2001; Caorsi et al. 2011; Toepfer et al. 2013). RLC dissociates spontaneously from the myosin heavy chain and diffuses out of the filament lattice (Yang and Sweeney 1995). Addition of RLC to the bathing medium of RLC-extracted permeabilized muscle cells restores functional activity as measured by calcium-dependent force generation and relaxation and velocity-dependent force generation, indicating that RLC effectively re-binds to its myosin target. RLC extraction of up to $80 \%$ can be achieved, accompanied by some extraction of myosin-binding protein $\mathrm{C}$ and of troponin components, principally TnC (Toepfer et al. 2013). Inclusion of troponin and MyBP-C in the incubation medium improves the recovery of physiological function as these proteins also reversibly dissociate from the myofilament during RLC exchange and are replenished from the incubation medium. Moreover, as shown recently (Kampourakis and Irving 2015), either chemical permeabilization procedures using detergents (Triton X-100) or treatment of the tissue with solutions containing EGTA (ethylene glycol tetraacetic acid) or BDM (2,3-butanedione monoxime) have no effect on the RLC phosphorylation level. The RLC exchange procedure in chemically permeabilized or demembranated muscle fibers or myofibrils is therefore convenient, and provides precise control of phosphorylation levels of RLC incorporated into the filament lattice. This avoids complications resulting from inadvertent changes in the phosphorylation levels of other sarcomeric proteins, as would be the case if the kinases or phosphatases are added directly to the permeabilized cells. This method also has the advantage that RLC carrying mutations or RLC that have been engineered to carry fluorescent reporters at specific sites can readily be introduced into the muscle fibres or myofibrils. However, in vitro phosphorylation may not mimic the in vivo MLCK activity as the kinases may target different sites depending on whether phosphorylation occurs in vivo or in vitro.

Reduction of phosphorylation is achieved using selective apoptotic agents targeting MLCK, as has been shown in smooth muscle cells (Fazal et al. 2005). Moreover, MLCK inhibitors such as $50 \mu \mathrm{M}$ of ML-9 and $400 \mu \mathrm{M}$ of nonapeptide rkkykyrrk-NH2 (D-PIK) are used to reduce RLC phosphorylation in vitro (Feighery et al. 2008). Another method for reducing RLC phosphorylation is by transfecting cultured cells with anti-sense MLCK, as used by Petrache et al. who found that caspase-dependent cleavage of MLCK was implicated in pulmonary endothelial cell apoptosis (Petrache et al. 2003). Caspase-mediated cleavage of MLCK as used in this study could potentially be used as another tool for inhibiting MLCK and reducing RLC phosphorylation in striated muscle in vitro. Inhibitory antibodies against MLCK to block RLC phosphorylation are used, but the effectiveness and reliability of this method depend on the specificity of the antibodies (Fazal et al. 2005).

Other commonly used kinases for RLC phosphorylation are Rho-associated kinase (Rho-kinase) and protein kinase C (PKC). Rho-kinase is also involved in RLC phosphorylation in striated muscle. For example, adult rat ventricular myocytes were treated with the Rho-kinase inhibitor Y-27632 at a concentration of $10 \mu \mathrm{M}$ so that it does not phosphorylate the myosin-binding phosphatase targeting subunit (MYPT), the catalytic subunit of protein phosphatase 1 (PP1) (Rajashree et al. 2005). This results in inhibition of RLC phosphorylation. It used an antibody (12896, Santa Cruz) to target phosphor-Thr18 and Ser19, which are phosphorylation sites of smooth muscle and non-muscle cells. It should be verified by antibody that targets phosphor-Ser 15. However, this study still suggests an important role for $\alpha$-adrenergic signaling in modulation of RLC phosphorylation via inhibition of the myosin phosphatase.

The phosphorylation pattern of cRLC by PKC is different from that by MLCK (Scruggs and Solaro 2011) (Venema et al. 1993). In adult rat heart myofibrils in vitro, PKC mediated a phosphorylation of RLC with a stoichiometry ( $0.7 \mathrm{~mol}$ of phosphate/mol of protein) similar to that mediated by MLCK (Venema et al. 1993).

Other kinases such as p21-activated kinase (PAK) and P34 kinase also affect RLC phosphorylation, but most reports refer to smooth muscle and non-muscle cells (Chu et al. 2013).

For example, $\gamma$-PAK, that is activated by GTP-binding proteins $\mathrm{Cdc} 42$ and Rac, catalyses phosphorylation of intact non-muscle myosin-II and isolated recombinant RLC (Chu et al. 2013). However, the PAK isoform of smooth muscle tissue, known as PAK1, affects RLC phosphorylation differently. By incubating guinea pig Triton-permeabilized smooth muscle tissue with active PAK1, it was found that PAK1 phosphorylates and inhibits smMLCK which reduces RLC phosphorylation. This, in turn, reduced the rate of smooth muscle contraction (Wirth et al. 2003). Purified P34 kinase (cyclin-p34cdc2) also phosphorylates RLC of cytoplasmic and smooth muscle myosin-II in vitro on Ser1 or Ser2 and Thr9 (Satterwhite et al. 1992). 
The procedures for using these kinases are similar to that for MLCK: incubation of the kinase with myosin RLC for 30 min at 4,25 , or $37^{\circ} \mathrm{C}$ (depending on the type of RLC) achieves a high level of phosphorylation (Satterwhite et al. 1992).

These in vitro smooth muscle strategies using various kinases can be applied to striated muscle by using the engineered recombinant RLC and exchanged into muscle fibers or myofibrils.

\section{Genetic engineering and pseudophosphorylation}

Genetic engineering is used to explore RLC expression and phosphorylation (Koga and Ikebe 2008; Lossie et al. 2012). Using RNA interference (RNAi) to interfere Rho1 (Rhokinase) expression in Drosophila S2 cells, the role of Rhokinase-dependent RLC phosphorylation in the localization of myosin was examined (Dean and Spudich 2006). The use of RNAi is powerful and versatile. Whole genome-wide maps of promoter and enhancer sequences for all genes open the door to targeted and controlled genetic expression to study their effects and functions with the caveat of potential secondary over- or under-expression effects on other genes in the cell due to false targets stemming from similarity in gene sequences. The technique could be utilized in cultured striated myocytes.

Pseudophosphorylation of RLC is another genetic approach to modulate phosphorylation. This technique is the same as discussed above, but is also used in vitro to engineer recombinant RLC. Pseudophosphorylated RLC is studied by in vitro biochemical techniques or is exchanged into muscle fibers (Muthu et al. 2014). (See above "In vivo modifications" section for details).

\section{Chemical and biological factors}

Chemical and biological factors inhibit myosin light chain phosphatase or activate phosphorylation of RLC via signaling pathways. Yamakita performed in situ phosphorylation of smooth muscle and non-muscle RLC in dividing REF$4 \mathrm{~A}$ cells using $\left[{ }^{32} \mathrm{p}\right]$ orthophosphoric acid (Yamakita et al. 1994). At a concentration of $1 \mathrm{U} / \mathrm{ml}$, thrombin, which is a serine protease, induces a prolonged increase in the phosphorylation of RLC, reaching a peak after $1 \mathrm{~min}$ of exposure to thrombin and maintaining elevated phosphorylation for at least $30 \mathrm{~min}$ (Amerongen et al. 1998; Richardson et al. 2000). These strategies can also be used in striated muscle cells to modulate RLC phosphorylation levels. For instance, myofibrils from rabbit psoas muscle are dephosphorylated completely by incubation in glycerinating solution containing $4 \mathrm{mM}$ ATP incubating for $60 \mathrm{~min}$ at $24{ }^{\circ} \mathrm{C}$. Subsequently, phosphorylated muscle is prepared by inhibiting the activity of phosphatase with the addition of
$20 \mathrm{mM} \mathrm{NaF}$ and in the presence of $20 \mathrm{mM}$ phosphate along with 5 mM ATP (Stewart et al. 2010).

\section{Chemical genetic approach}

Genetic or a pharmacological approaches alone (discussed above) have several disadvantages, especially when targeting a specific kinase to modulate RLC or other sarcomeric protein phosphorylation. Since the ATP-binding sites of kinases are highly conserved, it is difficult to target kinases specifically using pharmacological inhibitors. On the other hand, genetic approaches to deactivate kinases are very specific but take time to be effective and levels of inactivation are difficult to control. Small molecule pharmacological inhibitors inactivate kinases rapidly and in a dose-dependent manner. Moreover, interpretation of results using genetic or pharmacological techniques is complicated by functional redundancy of kinases and the overlapping substrates of multiple kinases. To overcome this, Kevan Shokat and his colleagues (Garske et al. 2011) developed a chemical genetic approach. A mutation is created to change a conserved hydrophobic amino acid acting as a gatekeeper in the active site of kinases to a small amino acid such as alanine or glycine to generate a uniquely targetable mutant kinase. This mutated kinase can then be targeted with chemically bulky analogs of natural kinase inhibitors to occupy the new enlarged pocket of the gatekeeper site, whereas wild-type kinases will not be inhibited. The effectiveness of the method depends on a mutation that retains kinase activity, which is not achieved in $\sim 30 \%$ of cases. Moreover, non-covalent inhibitor binding limits the power of this method. An alternate method which does not involve bulky amino acid substitution is the engineering of a cysteine gatekeeper in the active site that can be inhibited with an electrophilic inhibitor. The advantage of a cysteine gatekeeper is that it is rare in the kinome and is inherently hydrophobic in nature as well. This strategy achieves specificity via shape complementarity.

This chemical genetic approach has been exploited to identify RLC as a direct substrate for phosphorylation by ZIP kinase to regulate smooth muscle contraction (Moffat et al. 2011). A ZIP-L93G mutant kinase was created that is capable of utilizing a bulky analog of ATP $\left(\mathrm{P}^{32}\right.$ labeled 6-phenyl-ATP) as substrate. Using SDS-PAGE and autoradiography, RLC was found to be the direct substrate of ZIP kinase in situ. Thus, this approach manipulates RLC phosphorylation in different tissue systems by selectively inhibiting kinases.

\section{Physico-chemical methods}

Physico-chemical methods involve the use of physical perturbation such as microinjection, stretch, and protein 
exchange to incorporate proteins or factors in vitro to modulate RLC phosphorylation. These methods are used in striated muscle and non-muscle cells. Zeng et al. used two physical methods to modify phosphorylation of RLC (Zeng et al. 2000). The first method was microinjection of PAK2 into endothelial cells which increased the phosphorylated RLC from $0.2 \mathrm{~mol} \mathrm{PO}_{4} / \mathrm{mol}$ to $0.37 \mathrm{~mol} \mathrm{PO}_{4} / \mathrm{mol} \mathrm{RLC}$ in $35 \mathrm{~min}$. Moreover, the reaction was specific for monophosphorylation of RLC but not for di-phosphorylation. The second method was by constitutively delivering active PAK2 into bovine pulmonary artery endothelial cytosol by using the osmotic delivery method developed by Okada and Rechsteiner (1982).

Toepfer et al. exchanged native RLC with recombinant RLC phosphorylated in vitro by MLCK and ZIP-kinase into permeabilized trabeculae of the rat heart using the technique developed in Irving and Goldman laboratories (Colson et al. 2010; Toepfer et al. 2013). Trabecular muscle was incubated in three sequential 15-min incubations at $20{ }^{\circ} \mathrm{C}$ with fresh $0.5 \mathrm{mg} / \mathrm{ml}$ RLC exchange solution incorporating $0.5 \mathrm{mg} / \mathrm{ml} \mathrm{TnC}$, to reintroduce $\mathrm{TnC}$ that is lost during exchange so as not to alter contractile characteristics of the preparations (Borejdo et al. 2001). Temperature is important for the exchange method because higher temperature causes higher tension, which may damage the muscle. Albeit, in Toepfer et al., exchange was done in the presence of $5 \mathrm{mM} \mathrm{MgATP}$ and without calcium (relaxing condition), thus technically no active tension was developed in the muscle fiber. This technique increases the RLC phosphorylation level by about $40 \%$ at $20{ }^{\circ} \mathrm{C}$. The physical exchange method benefits from the ability to introduce fluorescent dyes at specific sites in the recombinant RLC at the same time. The fluorescence signal is helpful to track the extent of exchange. The exchange method can also be applied to ELC (Ushakov et al. 2011), but suitable, reversible conditions are more difficult to establish.

Stretch stimuli on muscle cells have been shown to modulate RLC phosphorylation levels in smooth muscle. In the canine basilar artery, stretch increases smooth muscle RLC tri-phosphorylation at MLCK and PKC sites (Nakayama et al. 2003) indicating that stretch could regulate kinase activity. PKC $\alpha$ and PP2A (Protein phosphatase 2A) have physical and functional connection in smooth muscle cells (Azzi et al. 1998). A muscle pre-load stimulus achieved by stretching rabbit ventricular myocardium under physiological condition increases phosphorylation of RLC and other important sarcomeric components including tropomyosin and TnI (Monasky et al. 2010). This suggests that stretching intact muscle fibers modulates RLC phosphorylation physiologically. However, stretching alone is not specific and can cause biochemical alteration to various proteins in the sarcomere, not just RLC.
Applying isotropic compressive stress or shrinkage using a silicone chamber on murine $\mathrm{C} 2 \mathrm{C} 12$ skeletal myoblast cells dephosphorylates RLC via. RhoA phosphorylation by adenylyl cyclase/PKA (protein kinase A) pathway (Takemoto et al. 2015). Studies on adult striated muscle fibers are needed to reveal the role of mechano-sensation induced by stretch or compressive stress on the extent of RLC phosphorylation.

RLC phosphorylation is also correlated with the frequency of stimulation for cardiac muscle contraction (Dias et al. 2006; Silver et al. 1986). These studies reported that increasing stimulation frequency from 0 to 126 beats/min for $30 \mathrm{~min}$ produced a frequency-dependent increase in RLC phosphorylation from 0.1 to $0.4 \mathrm{~mol} \mathrm{Pi} / \mathrm{mol} \mathrm{RLC} \mathrm{in}$ perfused rabbit ventricular septae. Thus, frequency of stimulation modulates RLC phosphorylation in situ.

RLC phosphorylation is also correlated with temperature (Moore et al. 1990). Phosphorylation of RLC decreases with increasing incubation temperature of mammalian skeletal muscle fiber.

Commonly used in vitro RLC phosphorylation methods are compared and summarized in Table 3.

\section{Biomechanical measurements after RLC manipulation}

The functional effects of in vitro or in vivo manipulations of RLC phosphorylation need precise evaluation in a physiological setting that mimics the live tissue environment. In an ex vivo setting, measurement of the force response and the ATPase rate of the muscle fiber or the myofibril are needed. Single-filament biophysical experiments such as in vitro motility assays (Karabina et al. 2015), or spinlabeling combined with TIRF microscopy (Burghardt and Sikkink 2013) or laser-trap assays (Previs et al. 2014) provide important information at the molecular level, but single filament or studies of solubilized proteins lack the thick-thin filament sarcomeric lattice structure and suffer from the inability to measure a force response. Moreover, these experiments are not conducive to mimic the contraction cycle of cardiac beating by stretching or releasing per se. Chemically demembranated single muscle fibers or isolated single myofibrils offer ex vivo physiological systems in which RLC is readily exchanged (Borejdo et al. 2001; Caorsi et al. 2011) with controlled levels of phosphorylation. Permeabilized muscle fibers mounted between a force transducer and a piezo-motor or moving coil motor and are exposed to solutions to activate, relax, or put the fibers into rigor. Contraction of muscle fibers is activated by addition of calcium or by temperature-jump (T-jump), or by laser flash photolysis of NPE-caged ATP. The force response is measured directly using the force transducer, 


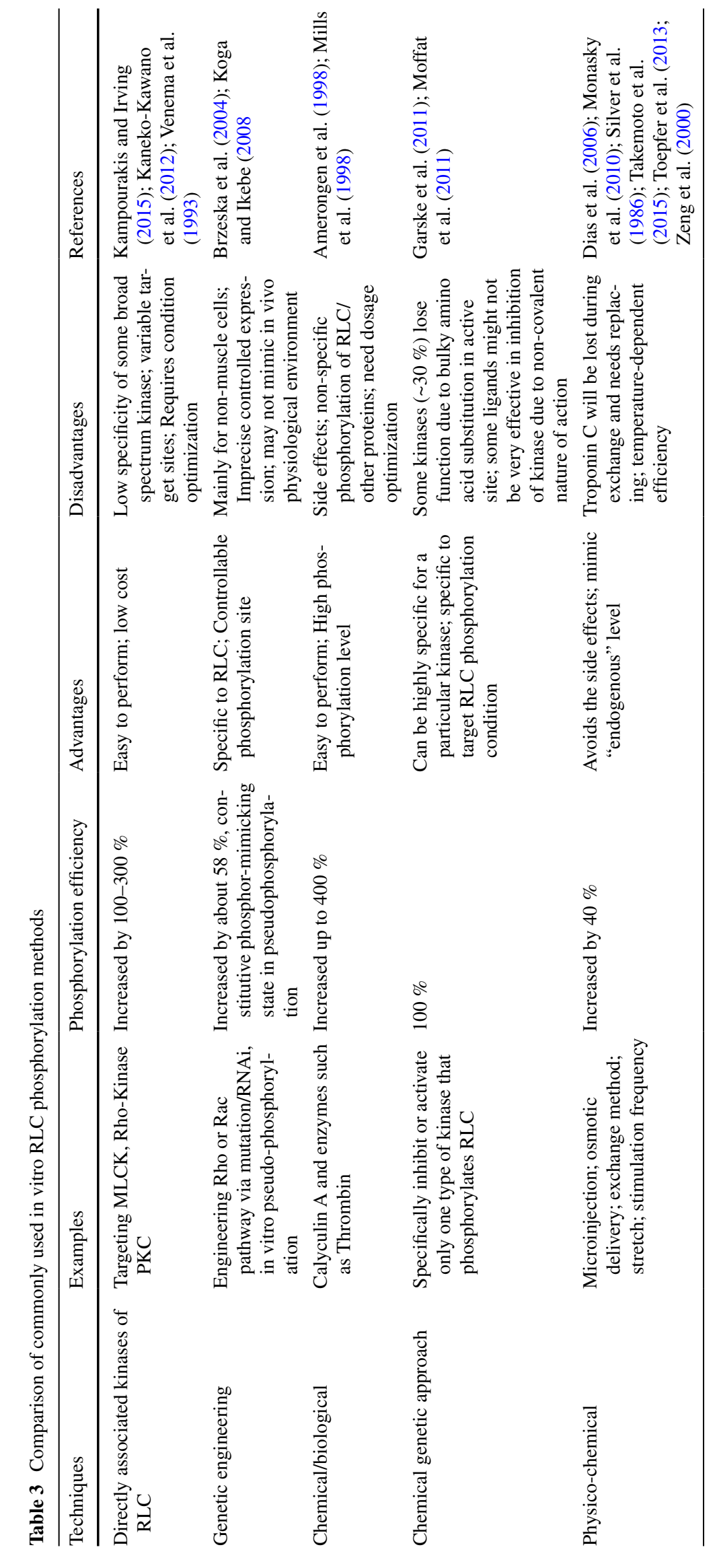


whereas actomyosin ATPase of the muscle is measured using a fluorescent phosphate sensor added to the bathing solution that rapidly binds phosphate after ATP breakdown. This provides measurement with millisecond time resolution. Stretch-release protocols explore the effect of force and ATPase before, during, or after stretch of muscle fibers to understand the effect of RLC phosphorylation in cardiac muscle during the heart beat cycle, or when using stretchrelease protocols in skeletal muscle as experienced during eccentric exercise such as jumping or sprinting (Bickham et al. 2011; He et al. 2000, 1997; Mansfield et al. 2012; Toepfer et al. 2013). Measurement of force exhibited by single myofibrils is measurable by taking advantage of myofibril adherence to clean glass needles with one of the needle attached to a piezomotor to stretch or release the myofibril. The other microneedle bends under the force produced by the myofibril. The microneedle bending is detected from the moving shadow of the needle, illuminated by a HeNe laser, which is cast onto a double photodiode connected differentially. Thus the needle acts as a force transducer to report force generation by the myofibril. The myofibril is activated and relaxed using calcium-containing or calcium-free solution, respectively, by switching the laminar flow of solution flowing over the myofibril from a double-barreled pipette. The type of solution in which the myofibril is bathed depends on the position of the doublebarreled pipette (Song et al. 2013; Tesi et al. 2000, 2002; Vikhorev et al. 2014). Recombinant RLC exchange into myofibril to control phosphorylation and subsequent force responses under different conditions can be measured.

Step changes in length or force and ATPase rate measurements are routinely used to investigate the mechanical transduction process in muscle. Sinusoidal small amplitude length perturbation of the muscle fiber or myofibril over a range of frequencies has also been used to retrieve information on acto-myosin cross-bridge attachmentdetachment rates and muscle passive properties (Iorga et al. 2012; Miller et al. 2013). These techniques combined with exchange of RLC with manipulated phosphorylation can further help us understand the role of RLC phosphorylation in muscle contraction.

\section{Techniques to determine the site(s) and extent of RLC phosphorylation}

The measurement of in vivo RLC phosphorylation is still quite a challenge, as evidenced by the reported phosphorylation ratio of skRLC ranging from 5-40\% (Takashima 2009a). Considering the ubiquitous phosphatase activity in tissue, it is important to inhibit phosphatase when preparing sample for phosphorylation analysis. Methods to detect phosphorylation site(s) in normal and diseased tissue samples and for the measurement of the extent of phosphorylation are improving in terms of sensitivity, precision, and throughput. Some of the major approaches in phosphoproteomic analyses are protein mixture fractionation by gel electrophoresis, liquid chromatography, in tandem with phosphopeptide enrichment techniques coupled to mass spectrometry (MS) characterization.

In gel-based approaches, conventional two-dimensional electrophoresis (2DE) gel analysis is most common to detect phosphovariants of proteins according to their isoelectric point by isoelectric focusing and subsequently by molecular weight via SDS-PAGE (O'Farrell 1975). Phosphoproteins and their variants that have been separated by both charge and weight are visualized after staining (Steinberg 2009). For example, autoradiography using ${ }^{32} \mathrm{P} /{ }^{33} \mathrm{P}$ labeling of phosphate groups is possibly the most sensitive, albeit time-consuming, method. Immunoblotting using phospho-specific antibodies is extensively used to detect phospho-Tyr in proteins. The disadvantage is the low abundance of phospho-Tyr species, which makes them hard to detect, and phospho-Ser/Thr antibodies are known to have low specificity. Immunoblotting is performed using antibodies against RLC. Some RLC antibodies are specific for certain RLCs, i.e., cRLC and not smRLC, or specific for the animal type, i.e., human or mouse or rat. However, others are promiscuous, as the amino acid sequence they recognize is conserved across RLC types (Fig. 2).

Fluorescent stains specific for phosphoproteins are used in 1DE and 2DE gels. Pro-Q Diamond (Molecular Probes $^{\circledR}$ ) selectively stain phosphoproteins in acrylamide gels, without the need for blotting or phosphoprotein-specific antibodies and Western-blot analysis (Schulenberg et al. 2004; Steinberg 2009). Pro-Q stain is not quantitative, but can be used quantitatively if aided by sensitive mass spectrometry. Another technique uses a phosphate-binding tag (Phos-Tag), which binds specifically to phosphorylated ions and thus has a sensitivity to phosphoproteins that is similar to autoradiography. Phos-tag functions at neutral $\mathrm{pH}$ for the visualization of phosphorylated proteins in $1 \mathrm{DE}$ and 2DE gels (Kinoshita et al. 2006). Using Phos-tag gels, Marston and other groups found different phosphovariants of RLC in cardiac muscle tissues from normal and diseased states (Kinoshita et al. 2009; Toepfer et al. 2013). Moreover, Phos-tag SDS-PAGE can be used to clearly distinguish between thiophosphorylated and phosphorylated RLC as thiophosphorylated RLC migrates faster (Sutherland and Walsh 2012).

The 2DE gel system detects phosphorylation variants and phosphorylation sites (amount and location) as it can be conjugated with protease digestion and tandem mass spectrometry (also known as MS/MS) (Lin et al. 2010). For detection of very low phosphorylation levels in protein samples, phosphorylation enrichment of the sample is used 
before MS/MS detection. Analyses and detail descriptions can be found in the review by Dunn et al. (2010). Other than gel-based approaches, liquid chromatography along with MS gives sensitive separation and detection of phosphoproteins and phosphorylated sites. Affinity enrichment strategies such as immunoprecipitation and immune-affinity chromatography are used for purification of phosphoproteins followed by peptide fragmentation and MS/MS or tandem mass spectrometry to detect phosphorylation sites. The small molecular weight of RLCs and their acidic nature due to phosphorylation means that the species separate well in 2DE isoelectric focusing (IEF) gels, using tube gel electrophoresis with ampholytes of narrow $\mathrm{pH}$ range (4.5-5.4 pH range). The use of tube gels allows a comparatively large amount $(\sim 1 \mathrm{mg})$ of myofilament-enriched homogenate to be loaded, which permits the detection of low levels of phosphorylation or other post-translational modifications by MS or other methods (Westwood and Perry 1981). Analysis of the gel reveals variants based on their phosphorylation states: un-phosphorylated, monophosphorylated, and di-phosphorylated. This technique has been used to examine the phosphorylation of RLC in rabbit, rat, and mouse (Frearson et al. 1976).

The caveat of the 2DE system is that it is time consuming. A faster alternative is the 1DE Urea-Glycerol PAGE that has been extensively used for separating RLC species, especially from cardiac muscle tissue samples (Craig et al. 1987; Sobieszek 1986; Szczesna et al. 2002). Adding SDS and performing Urea/SDS-PAGE for cardiac samples has also been used for separating RLC phosphovariants (Kerrick et al. 2009; Muthu et al. 2012). This 1DE gel approach can be combined with western blot analysis by means of antibodies specific to the phosphorylated form of RLC (Davis et al. 2001). Moreover, these procedures are facilitated by selective extraction of RLC from the muscle homogenate before electrophoretic separation as described in the work of Davis et al. (Davis et al. 2001).

\section{Discussion and perspectives}

\section{In vivo manipulation}

Studying the function of RLC phosphorylation in vivo is a major advantage of transgenic techniques, to investigate the effect of phosphorylation from the molecular to the whole organism levels. Transgenic techniques may also allow studies of specific diseases in animal models. However, creating transgenic animals is time-consuming and their maintenance is expensive. A mutation introduced in the live animals may have resulted in the development of secondary unidentified changes which might compensate or accentuate the effects of the mutation, complicating the interpretation of the results. Also, the penetrance of the mutation may be variable and tissue specific (Cooper et al. 2013; Pereira et al. 1994).

Limiting expression levels using RNAi or transgenic targeting techniques may cause false positives because of interactions with multiple genes and isoforms of RLC or MLCK. For example, gene duplication and conversion events of mammalian RLC genes from smooth muscle, and non-muscle cells, lead to a high degree of sequence similarity and consequent difficulties for specific RNAi targeting or transgenesis. With regard to compensatory expression or modification of other proteins in cells carrying mutant constructs in transgenic animals, Scruggs et al. found that transgenically abolishing RLC phosphorylation reduces phosphorylation of both myosin binding protein $\mathrm{C}$ (MyBP-C) and TnI in cardiac muscle (Scruggs et al. 2009). These modifications could mask or amplify the effect of the original mutation. Minamisawa et al. demonstrated that a post-transcriptional compensatory program is triggered to maintain normal expression levels and functions even in a heterozygous mouse with a single dosage of ventricular RLC gene (Minamisawa et al. 1999).

Another disadvantage of the transgenic approach is the positional effect of the transgene. Depending on the landing location of the transgene in the genome, expression of other genes along with the transgene can be affected. In spite of these possible side effects, various protein-protein, biochemical, and chemo-mechanical interactions in the muscle and non-muscle tissues are deciphered by in vivo transgenics (Maughan et al. 2005). More recently, advanced technologies such as the phiC31 recombinase systems and the CRISPR/Cas9 system allow precise in vivo mutations or transgenesis in both invertebrates and vertebrates and have the potential to heal by gene therapy (Bischof et al. 2007; High et al. 2014; Imayoshi et al. 2013; Wang et al. 2013). These advances in in vivo genetic technologies will allow more precise in vivo targeting of RLC phosphorylation with regard to specific sites or specific chromosomal locations, or the targeting of specific kinases, which may open the possibility of therapeutic interventions.

In vivo pharmacological treatments are attractive approaches due to their simplicity. However, as Scruggs et al. found, abolishing RLC phosphorylation affects phosphorylation of both MyBP-C and TnI (Scruggs et al. 2009), and general administration of compounds such as AngII (Aoki et al. 2000) may have multiple effects that complicate experimental results and interpretations. In vivo propranolol injection in mice was initially used to dephosphorylate reported $\mathrm{TnI}$ in cardiac muscle (Vikhorev et al. 2014). The authors found the TnI phosphorylation was successfully reduced from 1.0 to $0.3 \mathrm{~mol} \mathrm{Pi} / \mathrm{mol} \mathrm{TnI}$ and was accompanied with a reduction in the phosphorylation level of MyBP-C from 2.9 to $0.25 \mathrm{~mol} \mathrm{Pi} / \mathrm{mol}$ MyBP-C, but 
has no effect on RLC phosphorylation (Chang et al. 2015). Thus, since RLC phosphorylation modulation could affect MyBP-C and TnI phosphorylation, propranolol treatment could be used as a negative control to change MyBP-C and TnI phosphorylation without affecting RLC phosphorylation. Although this approach depends on the level of protein dephosphorylation, it may establish the direct physiological and pharmacological effect of RLC phosphorylation on its own.

\section{In vitro manipulations}

Phosphorylation of RLC using an in vitro approach is faster than in vivo for studying mechanisms and for finding therapeutic targets or strategies to ameliorate muscle diseases. Targeting kinases like MLCK, and Rho-kinase, that are directly associated with RLC phosphorylation regulation is effective. The caveat in this approach is the assumption that the kinase acts on physiological in vivo target sites with similar effectiveness as in vitro, which might not be the case. Moreover, some recombinant kinases might have low specificity depending on the tissue origin or if they are bacteriologically expressed. Also, some kinases may have a broad functional spectrum. Therefore, optimization of the in vitro conditions to mimic the physiological environment as much as possible is needed. False positives or negatives might arise in genetic engineering, when using chemical/ biological agents such as calyculin A, or when applying chemical genetic approaches or physical methods. Nevertheless, due to their ease and speed, the in vitro techniques have definite advantages over in vivo approaches.

\section{The molecular players maintaining RLC phosphorylation/dephosphorylation balance}

Physiologically RLC phosphorylation in striated or smooth muscle is regulated by the balance of activities between MLCK and the myosin light chain phosphatase (MLCP). There are several molecular players that control this dynamic process. Along with regulation via MLCK activity (reviewed above), MLCP also keeps the activity balance (for detailed review see (Hartshorne et al. 2004). The major functional subunit of MLCP is the myosin phosphatase targeting protein 1 (MYPT1) in smooth muscle, and MYPT2 in skeletal and cardiac muscle. MLCP inhibition is regulated by agonist stimulation via various $\mathrm{G}$ protein-coupled receptors and RhoA and Rho-kinase pathways (Hartshorne et al. 1998; Somlyo and Somlyo 2003), mostly targeting the MYPT1 or MYPT2. An additional kinase that phosphorylates and inhibits MLCP is known as MPT1 kinase (Borman et al. 2002). Activation of MLCP is usually related to the increase in the levels of cAMP and cGMP dependent on the activity of protein kinase A/G (PKA and PKG). MLCP activation is known to be fulfilled by PKA/PKG phosphorylation of the MYPT1 in smooth muscle (Nakamura et al. 2007; Somlyo 2007) that opposes the inactivating RhoA/ Rho-kinase pathway.

Recently, a novel regulator named myosin phosphataseRho interacting protein (M-RIP) was identified in smooth muscle (Gebbink et al. 1997; Surks et al. 2003). M-RIP is a member of the MLCP complex, which associates with the myosin phosphatase targeting protein 1 (MYPT1), the regulatory- and myosin-binding subunit of MLCP. M-RIP directly binds to both RhoA and MLCP at adjacent sites to form the trimer. By binding to actin via the N-terminus, M-RIP links MLCP to the sarcomeric filaments to dephosphorylate RLC (Mulder et al. 2005). However, most of the studies explored smooth muscle cells and non-muscle cells (Riddick et al. 2008; Surks et al. 2005). Besides RNAi, another method described by Mahavadi et al. uses PKG to regulate phosphorylation (Mahavadi et al. 2014). It was found that PKG-induced phosphorylation of M-RIP enhances its association with MYPT1 to increase MLCP activity and RLC dephosphorylation. Thus, M-RIP is a target of PKG to mediate RLC dephosphorylation and smooth muscle relaxation. M-RIP is thus a potential target for modulating RLC phosphorylation in smooth muscle and possibly also in striated muscle.

In striated muscle too, MLCP activity balances the MLCK activity. It has been shown that RLC phosphorylation in fast twitch skeletal muscle fibers is slower than the twitch contraction but is faster than RLC dephosphorylation by MLCP (Sweeney et al. 1993). However, in cardiac muscle the rates of RLC phosphorylation and dephosphorylation are lower than in skeletal muscle, suggesting that this balancing activity is tissue specific and important for modulation of muscle contraction (Sweeney et al. 1993).

\section{Issues and future directions}

The role of striated muscle RLC phosphorylation in health and disease is an emerging question. The quest for understanding the mechanism by which RLC phosphorylation affects muscle function may lead to the development of therapeutic targets. Some of the major issues that need addressing are:

1. How does RLC phosphorylation affect the acto-myosin interactions, the structure of the myosin crossbridge and the ability of the muscle to generate force?

2. What are the molecular mechanisms by which naturally occurring mutations change RLC phosphorylation levels?

3. How do changes in RLC phosphorylation affect the phosphoproteome of the muscle cells, and how do 
these changes in phosphoproteome affect cellular behavior and the contractile machinery?

4. Do therapeutic modifications of the RLC phosphorylation level improve contractile performance in disease conditions?

5. What are the in vivo drivers that control RLC phosphorylation? Are these specific to RLC or shared with other proteins? How dynamic are the phosphorylation changes, and on what time scale do they operate?

To answer the above questions, a number of technologies will need to be applied, singly and in combination. Optical and electron microscopy may reveal structural changes brought about by changes in phosphorylation. Low-angle X-ray crystallography and FRET (Förster resonance energy transfer) studies may be used to observe the dynamics of cross-bridge interactions in different phosphorylation states of RLC. These studies may focus on the structure of the cross-bridges, but also in the inter-filament spacing and myofibrillar organization. Pseudophosphorylation may provide stable systems to aid structural studies and molecular dynamic simulations. Results will assist the elaboration of models of contraction in which the contractile performance and efficiency of muscle is related to disease states encountered in hypertrophic or dilated cardiomyopathies.

\section{Conclusions}

RLC phosphorylation regulates muscle contraction and other cellular functions, with important consequences for muscle behavior in health and disease. RLC phosphorylation plays a part in muscle disorders and may be a future therapeutic target. This review summarizes the structure and function of RLC and gives an overview of the methods available for manipulating and testing the effect of RLC phosphorylation in muscle tissue, focusing on striated muscle. We also compare the advantages and disadvantages of in vivo and in vitro methods and suggest their potential applications.

Acknowledgments This study was supported by a grant from Ministry of Education of Singapore (Moe Tier 2 2012-T2-2-105) and start-up grant to Michael A. Ferenczi from Lee Kong Chian School of Medicine, Nanyang Technological University. We thank Christopher Toepfer for helpful comments on the manuscript.

Open Access This article is distributed under the terms of the Creative Commons Attribution 4.0 International License (http://creativecommons.org/licenses/by/4.0/), which permits unrestricted use, distribution, and reproduction in any medium, provided you give appropriate credit to the original author(s) and the source, provide a link to the Creative Commons license, and indicate if changes were made.

\section{References}

Aguilar HN, Tracey CN, Tsang SC, McGinnis JM, Mitchell BF (2011) Phos-tag-based analysis of myosin regulatory light chain phosphorylation in human uterine myocytes. PLoS One 6:e20903

Alamo L, Li XE, Espinoza-Fonseca LM, Pinto A, Thomas DD, Lehman W, Padron R (2015) Tarantula myosin free head regulatory light chain phosphorylation stiffens N-terminal extension, releasing it and blocking its docking back. Mol BioSyst 11:2180-2189

Allen DG, Lamb GD, Westerblad H (2008) Skeletal muscle fatigue: cellular mechanisms. Physiol Rev 88:287-332

Amerongen GPvN, Draijer R, Vermeer MA, van Hinsbergh VWM (1998) Transient and prolonged increase in endothelial permeability induced by histamine and thrombin: role of protein kinases, calcium, and RhoA. Circ Res 83:1115-1123

Aoki H, Sadoshima J, Izumo S (2000) Myosin light chain kinase mediates sarcomere organization during cardiac hypertrophy in vitro. Nat Med 6:183-188

Atkinson SJ, Stewart M (1991) Molecular basis of myosin assembly: coiled-coil interactions and the role of charge periodicities. J Cell Sci Suppl 14:7-10

Azzi A, Aratri E, Boscoboinik D, Clement S, Ozer NK, Ricciarelli R, Spycher S (1998) Molecular basis of alpha-tocopherol control of smooth muscle cell proliferation. BioFactors 7:3-14

Baudry S, Duchateau J (2007) Postactivation potentiation in a human muscle: effect on the load-velocity relation of tetanic and voluntary shortening contractions. J Appl Physiol 103:1318-1325

Baumann BAJ, Taylor DW, Huang Z, Tama F, Fagnant PM, Trybus KM, Taylor KA (2012) Phosphorylated smooth muscle heavy meromyosin shows an open conformation linked to activation. J Mol Biol 415:274-287

Bengur AR, Robinson EA, Appella E, Sellers JR (1987) Sequence of the sites phosphorylated by protein kinase $\mathrm{C}$ in the smooth muscle myosin light chain. J Biol Chem 262:7613-7617

Bickham Dale C, West Timothy G, Webb Martin R, Woledge Roger C, Curtin Nancy A, Ferenczi Michael A (2011) Millisecondscale biochemical response to change in strain. Biophys $\mathrm{J}$ 101:2445-2454

Bischof J, Maeda RK, Hediger M, Karch F, Basler K (2007) An optimized transgenesis system for Drosophila using germline-specific phiC31 integrases. Proc Natl Acad Sci USA 104:3312-3317

Blumenthal DK, Stull JT (1980) Activation of skeletal muscle myosin light chain kinase by calcium $(2+)$ and calmodulin. Biochemistry 19:5608-5614

Borejdo J, Ushakov DS, Moreland R, Akopova I, Reshetnyak Y, Saraswat LD, Kamm K, Lowey S (2001) The power stroke causes changes in the orientation and mobility of the termini of essential light chain 1 of myosin. Biochemistry 40:3796-3803

Borman MA, MacDonald JA, Muranyi A, Hartshorne DJ, Haystead TA (2002) Smooth muscle myosin phosphatase-associated kinase induces $\mathrm{Ca}^{2+}$ sensitization via myosin phosphatase inhibition. J Biol Chem 277:23441-23446

Bowman BF, Peterson JA, Stull JT (1992) Pre-steady-state kinetics of the activation of rabbit skeletal muscle myosin light chain kinase by $\mathrm{Ca}^{2+} /$ calmodulin. J Biol Chem 267:5346-5354

Bresnick AR (1999) Molecular mechanisms of nonmuscle myosin-II regulation. Curr Opin Cell Biol 11:26-33

Brzeska H, Szczepanowska J, Matsumura F, Korn ED (2004) Racinduced increase of phosphorylation of myosin regulatory light chain in HeLa cells. Cell Motil Cytoskelet 58:186-199 
Burghardt TP, Sikkink LA (2013) Regulatory light chain mutants linked to heart disease modify the cardiac myosin lever arm. Biochemistry 52:1249-1259

Caorsi V, Ushakov DS, West TG, Setta-Kaffetzi N, Ferenczi MA (2011) FRET characterisation for cross-bridge dynamics in single-skinned rigor muscle fibres. Eur Biophys J 40:13-27

Chan JY, Takeda M, Briggs LE, Graham ML, Lu JT, Horikoshi N, Weinberg EO, Aoki H, Sato N, Chien KR, Kasahara H (2008) Identification of cardiac-specific myosin light chain kinase. Circ Res 102:571-580

Chang AN, Chen G, Gerard RD, Kamm KE, Stull JT (2010) Cardiac myosin is a substrate for zipper-interacting protein kinase (ZIPK). J Biol Chem 285:5122-5126

Chang AN, Huang J, Battiprolu PK, Hill JA, Kamm KE, Stull JT (2013) The effects of neuregulin on cardiac Myosin light chain kinase gene-ablated hearts. PLoS One 8:e66720

Chang AN, Battiprolu PK, Cowley PM, Chen G, Gerard RD, Pinto JR, Hill JA, Baker AJ, Kamm KE, Stull JT (2015) Constitutive phosphorylation of cardiac myosin regulatory light chain in vivo. J Biol Chem 290:10703-10716

Chu J, Pham NT, Olate N, Kislitsyna K, Day MC, LeTourneau PA, Kots A, Stewart RH, Laine GA, Cox CS Jr, Uray K (2013) Biphasic regulation of myosin light chain phosphorylation by p21-activated kinase modulates intestinal smooth muscle contractility. J Biol Chem 288:1200-1213

Cohen PT (2002) Protein phosphatase 1-targeted in many directions. J Cell Sci 115:241-256

Collins JH (1976) Homology of myosin DTNB light chain with alkali light chains, troponin $C$ and parvalbumin. Nature 259:699-700

Colson BA, Locher MR, Bekyarova T, Patel JR, Fitzsimons DP, Irving TC, Moss RL (2010) Differential roles of regulatory light chain and myosin binding protein-C phosphorylations in the modulation of cardiac force development. J Physiol 588:981-993

Colson BA, Gruber SJ, Thomas DD (2012) Structural dynamics of muscle protein phosphorylation. J Muscle Res Cell Motil $33: 419-429$

Cooke R (2011) The role of the myosin ATPase activity in adaptive thermogenesis by skeletal muscle. Biophys Rev 3:33-45

Cooper DN, Krawczak M, Polychronakos C, Tyler-Smith C, KehrerSawatzki H (2013) Where genotype is not predictive of phenotype: towards an understanding of the molecular basis of reduced penetrance in human inherited disease. Hum Genet 132:1077-1130

Craig R, Padron R, Kendrick-Jones J (1987) Structural changes accompanying phosphorylation of tarantula muscle myosin filaments. J Cell Biol 105:1319-1327

Davis JS, Hassanzadeh S, Winitsky S, Lin H, Satorius C, Vemuri R, Aletras AH, Wen H, Epstein ND (2001) The overall pattern of cardiac contraction depends on a spatial gradient of myosin regulatory light chain phosphorylation. Cell 107:631-641

Davis J, Hassanzadeh S, Winitsky S, Wen H, Aletras A, Epstein N (2002) A gradient of myosin regulatory light-chain phosphorylation across the ventricular wall supports cardiac torsion. In: Cold spring harbor symposia on quantitative biology, vol 67. Cold Spring Harbor Laboratory Press, New York, pp 345-352

Dean SO, Spudich JA (2006) Rho kinase's role in myosin recruitment to the equatorial cortex of mitotic Drosophila S2 cells is for myosin regulatory light chain phosphorylation. PLoS One $1: \mathrm{e} 131$

Dias FA, Walker LA, Arteaga GM, Walker JS, Vijayan K, Pena JR, Ke Y, Fogaca RT, Sanbe A, Robbins J, Wolska BM (2006) The effect of myosin regulatory light chain phosphorylation on the frequency-dependent regulation of cardiac function. J Mol Cell Cardiol 41:330-339

Dickinson MH, Hyatt CJ, Lehmann FO, Moore JR, Reedy MC, Sim$\operatorname{cox}$ A, Tohtong R, Vigoreaux JO, Yamashita H, Maughan DW
(1997) Phosphorylation-dependent power output of transgenic flies: an integrated study. Biophys J 73:3122-3134

Ding P, Huang J, Battiprolu PK, Hill JA, Kamm KE, Stull JT (2010) Cardiac myosin light chain kinase is necessary for myosin regulatory light chain phosphorylation and cardiac performance in vivo. J Biol Chem 285:40819-40829

Driska SP, Aksoy MO, Murphy RA (1981) Myosin light chain phosphorylation associated with contraction in arterial smooth muscle. Am J Physiol 240:C222-C233

Duggal D, Nagwekar J, Rich R, Midde K, Fudala R, Gryczynski I, Borejdo J (2014) Phosphorylation of myosin regulatory light chain has minimal effect on kinetics and distribution of orientations of cross bridges of rabbit skeletal muscle. Am J Physiol Regul Integr Comp Physiol 306:R222-R233

Dunn JD, Reid GE, Bruening ML (2010) Techniques for phosphopeptide enrichment prior to analysis by mass spectrometry. Mass Spectrom Rev 29:29-54

Espinoza-Fonseca LM, Kast D, Thomas DD (2007) Molecular dynamics simulations reveal a disorder-to-order transition on phosphorylation of smooth muscle myosin. Biophys $\mathbf{J}$ 93:2083-2090

Espinoza-Fonseca LM, Kast D, Thomas DD (2008) Thermodynamic and structural basis of phosphorylation-induced disorder-toorder transition in the regulatory light chain of smooth muscle myosin. J Am Chem Soc 130:12208-12209

Espinoza-Fonseca LM, Alamo L, Pinto A, Thomas DD, Padrón R (2015) Sequential myosin phosphorylation activates tarantula thick filament via a disorder-order transition. Mol BioSyst 11:2167-2179

Farman GP, Miller MS, Reedy MC, Soto-Adames FN, Vigoreaux JO, Maughan DW, Irving TC (2009) Phosphorylation and the $\mathrm{N}$-terminal extension of the regulatory light chain help orient and align the myosin heads in Drosophila flight muscle. J Struct Biol 168:240-249

Fazal F, Gu L, Ihnatovych I, Han Y, Hu W, Antic N, Carreira F, Blomquist JF, Hope TJ, Ucker DS, de Lanerolle P (2005) Inhibiting myosin light chain kinase induces apoptosis in vitro and in vivo. Mol Cell Biol 25:6259-6266

Feighery LM, Cochrane SW, Quinn T, Baird AW, O'Toole D, Owens SE, O’Donoghue D, Mrsny RJ, Brayden DJ (2008) Myosin light chain kinase inhibition: correction of increased intestinal epithelial permeability in vitro. Pharm Res 25:1377-1386

Ferenczi MA (2000) Micromechanical measurements on biological materials: muscle fibres. Biotechnol Lett 22:521-529

Frearson N, Solaro RJ, Perry SV (1976) Changes in phosphorylation of $\mathrm{P}$ light chain of myosin in perfused rabbit heart. Nature 264:801-802

Frey N, Olson EN (2003) Cardiac hypertrophy: the good, the bad, and the ugly. Annu Rev Physiol 65:45-79

Gallagher PJ, Herring BP, Griffin SA, Stull JT (1991) Molecular characterization of a mammalian smooth muscle myosin light chain kinase. J Biol Chem 266:23936-23944

Garske AL, Peters U, Cortesi AT, Perez JL, Shokat KM (2011) Chemical genetic strategy for targeting protein kinases based on covalent complementarity. Proc Natl Acad Sci USA 108:15046-15052

Gebbink MF, Kranenburg O, Poland M, van Horck FP, Houssa B, Moolenaar WH (1997) Identification of a novel, putative rho-specific GDP/GTP exchange factor and a RhoAbinding protein: control of neuronal morphology. J Cell Biol 137:1603-1613

Gittings W, Bunda J, Stull JT, Vandenboom R (2016) Interaction of posttetanic potentiation and the catchlike property in mouse skeletal muscle. Muscle Nerve. doi:10.1002/mus.25053

Granzier HL, de Tombe PP (2015) Myosin light chain phosphorylation to the rescue. Proc Natl Acad Sci USA 112:9148-9149 
Gratecos D, Fischer EH (1974) Adenosine 5'-O(3-thiotriphosphate) in the control of phosphorylase activity. Biochem Biophys Res Commun 58:960-967

Greenberg MJ, Mealy TR, Watt JD, Jones M, Szczesna-Cordary D, Moore JR (2009) The molecular effects of skeletal muscle myosin regulatory light chain phosphorylation. Am J Physiol Regul Integr Comp Physiol 297:R265-R274

Hartman MA, Spudich JA (2012) The myosin superfamily at a glance. J Cell Sci 125:1627-1632

Hartshorne DJ, Ito M, Erdodi F (1998) Myosin light chain phosphatase: subunit composition, interactions and regulation. J Muscle Res Cell Motil 19:325-341

Hartshorne DJ, Ito M, Erdödi F (2004) Role of protein phosphatase type 1 in contractile functions: myosin phosphatase. J Biol Chem 279:37211-37214

He ZH, Chillingworth RK, Brune M, Corrie JE, Trentham DR, Webb MR, Ferenczi MA (1997) ATPase kinetics on activation of rabbit and frog permeabilized isometric muscle fibres: a real time phosphate assay. J Physiol 501(Pt 1):125-148

He ZH, Bottinelli R, Pellegrino MA, Ferenczi MA, Reggiani C (2000) ATP consumption and efficiency of human single muscle fibers with different myosin isoform composition. Biophys J 79:945-961

He WQ, Peng YJ, Zhang WC, Lv N, Tang J, Chen C, Zhang CH, Gao S, Chen HQ, Zhi G, Feil R, Kamm KE, Stull JT, Gao X, Zhu MS (2008) Myosin light chain kinase is central to smooth muscle contraction and required for gastrointestinal motility in mice. Gastroenterology 135:610-620

Hernandez OM, Jones M, Guzman G, Szczesna-Cordary D (2007) Myosin essential light chain in health and disease. Am J Physiol Heart Circ Physiol 292:H1643-H1654

Herring BP, England PJ (1986) The turnover of phosphate bound to myosin light chain-2 in perfused rat heart. Biochem $\mathrm{J}$ 240:205-214

Herring BP, Dixon S, Gallagher PJ (2000) Smooth muscle myosin light chain kinase expression in cardiac and skeletal muscle. Am J Physiol Cell Physiol 279:C1656-C1664

High K, Gregory PD, Gersbach C (2014) CRISPR technology for gene therapy. Nat Med 20:476-477

Hooijman P, Stewart MA, Cooke R (2011) A new state of cardiac myosin with very slow ATP turnover: a potential cardioprotective mechanism in the heart. Biophys J 100:1969-1976

Huang J, Shelton JM, Richardson JA, Kamm KE, Stull JT (2008) Myosin regulatory light chain phosphorylation attenuates cardiac hypertrophy. J Biol Chem 283:19748-19756

Ihara E, MacDonald JA (2007) The regulation of smooth muscle contractility by zipper-interacting protein kinase. Can J Physiol Pharmacol 85:79-87

Ikebe M, Stepinska M, Kemp BE, Means AR, Hartshorne DJ (1987) Proteolysis of smooth muscle myosin light chain kinase. Formation of inactive and calmodulin-independent fragments. J Biol Chem 262:13828-13834

Imayoshi I, Tabuchi S, Hirano K, Sakamoto M, Kitano S, Miyachi H, Yamanaka A, Kageyama R (2013) Light-induced silencing of neural activity in Rosa26 knock-in mice conditionally expressing the microbial halorhodopsin eNpHR2.0. Neurosci Res 75:53-58

Iorga B, Wang L, Stehle R, Pfitzer G, Kawai M (2012) ATP binding and cross-bridge detachment steps during full $\mathrm{Ca}^{(2)(+)}$ activation: comparison of myofibril and muscle fibre mechanics by sinusoidal analysis. J Physiol 590:3361-3373

Irving M, Lombardi V, Piazzesi G, Ferenczi MA (1992) Myosin head movements are synchronous with the elementary force-generating process in muscle. Nature 357:156-158

Irving M, Piazzesi G, Lucii L, Sun Y-B, Harford JJ, Dobbie IM, Ferenczi MA, Reconditi M, Lombardi V (2000) Conformation of the myosin motor during force generation in skeletal muscle. Nat Struct Mol Biol 7:482-485

Jiang Y, Wang Y, Wang T, Hawke DH, Zheng Y, Li X, Zhou Q, Majumder S, Bi E, Liu DX, Huang S, Lu Z (2014) PKM2 phosphorylates MLC2 and regulates cytokinesis of tumour cells. Nat Commun 5:5566

Kamm KE, Stull JT (2011) Signaling to myosin regulatory light chain in sarcomeres. J Biol Chem 286:9941-9947

Kampourakis T, Irving M (2015) Phosphorylation of myosin regulatory light chain controls myosin head conformation in cardiac muscle. J Mol Cell Cardiol 85:199-206

Kaneko-Kawano T, Takasu F, Naoki H, Sakumura Y, Ishii S, Ueba T, Eiyama A, Okada A, Kawano Y, Suzuki K (2012) Dynamic regulation of myosin light chain phosphorylation by rho-kinase. PLoS One 7:e39269

Karabina A, Kazmierczak K, Szczesna-Cordary D, Moore JR (2015) Myosin regulatory light chain phosphorylation enhances cardiac beta-myosin in vitro motility under load. Arch Biochem Biophys 580:14-21

Karatzaferi C, Franks-Skiba K, Cooke R (2008) Inhibition of shortening velocity of skinned skeletal muscle fibers in conditions that mimic fatigue. Am J Physiol Regul Integr Comp Physiol 294:R948-R955

Kass DA, Solaro RJ (2006) Mechanisms and use of calcium-sensitizing agents in the failing heart. Circulation 113:305-315

Kensler RW, Shaffer JF, Harris SP (2011) Binding of the $N$-terminal fragment $\mathrm{C} 0-\mathrm{C} 2$ of cardiac MyBP-C to cardiac F-actin. J Struct Biol 174:44-51

Kerrick WG, Kazmierczak K, Xu Y, Wang Y, Szczesna-Cordary D (2009) Malignant familial hypertrophic cardiomyopathy D166V mutation in the ventricular myosin regulatory light chain causes profound effects in skinned and intact papillary muscle fibers from transgenic mice. FASEB J 23:855-865

Kinoshita E, Kinoshita-Kikuta E, Takiyama K, Koike T (2006) Phosphate-binding tag, a new tool to visualize phosphorylated proteins. Mol Cell Proteomics 5:749-757

Kinoshita E, Kinoshita-Kikuta E, Koike T (2009) Separation and detection of large phosphoproteins using Phos-tag SDS-PAGE. Nat Protoc 4:1513-1521

Koga Y, Ikebe M (2008) A novel regulatory mechanism of myosin light chain phosphorylation via binding of 14-3-3 to myosin phosphatase. Mol Biol Cell 19:1062-1071

Kubalak SW, Miller-Hance WC, O'Brien TX, Dyson E, Chien KR (1994) Chamber specification of atrial myosin light chain-2 expression precedes septation during murine cardiogenesis. J Biol Chem 269:16961-16970

Kuhbandner S, Brummer S, Metzger D, Chambon P, Hofmann F, Feil $\mathrm{R}$ (2000) Temporally controlled somatic mutagenesis in smooth muscle. Genesis 28:15-22

Kumar CC, Cribbs L, Delaney P, Chien KR, Siddiqui MA (1986) Heart myosin light chain 2 gene. Nucleotide sequence of full length cDNA and expression in normal and hypertensive rat. $\mathbf{J}$ Biol Chem 261:2866-2872

Levine RJ, Kensler RW, Yang Z, Stull JT, Sweeney HL (1996) Myosin light chain phosphorylation affects the structure of rabbit skeletal muscle thick filaments. Biophys J 71:898-907

Lin J, Xie Z, Zhu H, Qian J (2010) Understanding protein phosphorylation on a systems level. Brief Funct Genom 9:32-42

Lossie J, Ushakov DS, Ferenczi MA, Werner S, Keller S, Haase H, Morano I (2012) Mutations of ventricular essential myosin light chain disturb myosin binding and sarcomeric sorting. Cardiovasc Res 93:390-396

Lyon AR, MacLeod KT, Zhang Y, Garcia E, Kanda GK, Lab MJ, Korchev YE, Harding SE, Gorelik J (2009) Loss of T-tubules and other changes to surface topography in ventricular 
myocytes from failing human and rat heart. Proc Natl Acad Sci USA 106:6854-6859

Mahavadi S, Nalli A, Al-Shboul O, Murthy KS (2014) Inhibition of MLC20 phosphorylation downstream of $\mathrm{Ca}^{2+}$ and RhoA: a novel mechanism involving phosphorylation of myosin phosphatase interacting protein (M-RIP) by PKG and stimulation of MLC phosphatase activity. Cell Biochem Biophys 68:1-8

Mansfield C, West TG, Curtin NA, Ferenczi MA (2012) Stretch of contracting cardiac muscle abruptly decreases the rate of phosphate release at high and low calcium. J Biol Chem 287(31):25696-25705

Matsumura F, Totsukawa G, Yamakita Y, Yamashiro S (2001) Role of myosin light chain phosphorylation in the regulation of cytokinesis. Cell Struct Funct 26:639-644

Maughan DW, Henkin JA, Vigoreaux JO (2005) Concentrations of glycolytic enzymes and other cytosolic proteins in the diffusible fraction of a vertebrate muscle proteome. Mol Cell Proteom 4:1541-1549

Midde K, Rich R, Marandos P, Fudala R, Li A, Gryczynski I, Borejdo J (2013) Comparison of orientation and rotational motion of skeletal muscle cross-bridges containing phosphorylated and dephosphorylated myosin regulatory light chain. J Biol Chem 288:7012-7023

Miller MS, Farman GP, Braddock JM, Soto-Adames FN, Irving TC, Vigoreaux JO, Maughan DW (2011) Regulatory light chain phosphorylation and $N$-terminal extension increase cross-bridge binding and power output in Drosophila at in vivo myofilament lattice spacing. Biophys J 100:1737-1746

Miller MS, Bedrin NG, Callahan DM, Previs MJ, Jennings ME 2nd, Ades PA, Maughan DW, Palmer BM, Toth MJ (2013) Agerelated slowing of myosin actin cross-bridge kinetics is sex specific and predicts decrements in whole skeletal muscle performance in humans. J Appl Physiol (1985) 115:1004-1014

Mills JC, Stone NL, Erhardt J, Pittman RN (1998) Apoptotic membrane blebbing is regulated by myosin light chain phosphorylation. J Cell Biol 140:627-636

Minamisawa S, Gu Y, Ross J Jr, Chien KR, Chen J (1999) A posttranscriptional compensatory pathway in heterozygous ventricular myosin light chain 2-deficient mice results in lack of gene dosage effect during normal cardiac growth or hypertrophy. $\mathbf{J}$ Biol Chem 274:10066-10070

Miyata S, Minobe W, Bristow MR, Leinwand LA (2000) Myosin heavy chain isoform expression in the failing and nonfailing human heart. Circ Res 86:386-390

Moffat LD, Brown SB, Grassie ME, Ulke-Lemee A, Williamson LM, Walsh MP, MacDonald JA (2011) Chemical genetics of zipperinteracting protein kinase reveal myosin light chain as a bona fide substrate in permeabilized arterial smooth muscle. J Biol Chem 286:36978-36991

Monasky MM, Biesiadecki BJ, Janssen PM (2010) Increased phosphorylation of tropomyosin, troponin I, and myosin light chain-2 after stretch in rabbit ventricular myocardium under physiological conditions. J Mol Cell Cardiol 48:1023-1028

Moore RL, Stull JT (1984) Myosin light chain phosphorylation in fast and slow skeletal muscles in situ. Am J Physiol 247:C462-C471

Moore RL, Palmer BM, Williams SL, Tanabe H, Grange RW, Houston ME (1990) Effect of temperature on myosin phosphorylation in mouse skeletal muscle. Am J Physiol 259:C432-C438

Morano I (1992) Effects of different expression and posttranslational modifications of myosin light chains on contractility of skinned human cardiac fibers. Basic Res Cardiol 87(Suppl 1):129-141

Morano I (1999) Tuning the human heart molecular motors by myosin light chains. J Mol Med 77:544-555

Morano I, Hofmann F, Zimmer M, Ruegg JC (1985) The influence of P-light chain phosphorylation by myosin light chain kinase on the calcium sensitivity of chemically skinned heart fibres. FEBS Lett 189:221-224

Mulder J, Ariaens A, van Horck FP, Moolenaar WH (2005) Inhibition of RhoA-mediated SRF activation by p116Rip. FEBS Lett 579:6121-6127

Muthu P, Kazmierczak K, Jones M, Szczesna-Cordary D (2012) The effect of myosin RLC phosphorylation in normal and cardiomyopathic mouse hearts. J Cell Mol Med 16:911-919

Muthu P, Liang J, Schmidt W, Moore JR, Szczesna-Cordary D (2014) In vitro rescue study of a malignant familial hypertrophic cardiomyopathy phenotype by pseudo-phosphorylation of myosin regulatory light chain. Arch Biochem Biophys 552-553:29-39

Nakamura K, Koga Y, Sakai H, Homma K, Ikebe M (2007) cGMPdependent relaxation of smooth muscle is coupled with the change in the phosphorylation of myosin phosphatase. Circ Res 101:712-722

Nakayama K, Obara K, Tanabe Y, Ishikawa T (2003) 20-Hydroxyeicosatetraenoic acid potentiates contractile activation of canine basilar artery in response to stretch via protein kinase Calphamediated inhibition of calcium-activated potassium channel. Adv Exp Med Biol 538:411-416 (discussion 416)

Nonaka M, Morimoto S, Murayama T, Kurebayashi N, Li L, Wang YY, Arioka M, Yoshihara T, Takahashi-Yanaga F, Sasaguri T (2015) Stage-dependent benefits and risks of pimobendan in mice with genetic dilated cardiomyopathy and progressive heart failure. Br J Pharmacol 172:2369-2382

O'Farrell PH (1975) High resolution two-dimensional electrophoresis of proteins. J Biol Chem 250:4007-4021

Okada CY, Rechsteiner M (1982) Introduction of macromolecules into cultured mammalian cells by osmotic lysis of pinocytic vesicles. Cell 29:33-41

Olsson MC, Patel JR, Fitzsimons DP, Walker JW, Moss RL (2004) Basal myosin light chain phosphorylation is a determinant of $\mathrm{Ca}^{2+}$ sensitivity of force and activation dependence of the kinetics of myocardial force development. Am J Physiol Heart Circ Physiol 287:H2712-H2718

Pasparakis G, Krasnogor N, Cronin L, Davis BG, Alexander C (2010) Controlled polymer synthesis-from biomimicry towards synthetic biology. Chem Soc Rev 39:286-300

Pearson RB, Jakes R, John M, Kendrick-Jones J, Kemp BE (1984) Phosphorylation site sequence of smooth muscle myosin light chain $(\mathrm{Mr}=20,000)$. FEBS Lett 168:108-112

Peng Y, Gregorich ZR, Valeja SG, Zhang H, Cai W, Chen YC, Guner H, Chen AJ, Schwahn DJ, Hacker TA, Liu X, Ge Y (2014) Top-down proteomics reveals concerted reductions in myofilament and Z-disc protein phosphorylation after acute myocardial infarction. Mol Cell Proteom 13:2752-2764

Pereira R, Halford K, Sokolov BP, Khillan JS, Prockop DJ (1994) Phenotypic variability and incomplete penetrance of spontaneous fractures in an inbred strain of transgenic mice expressing a mutated collagen gene (COL1A1). J Clin Invest 93:1765-1769

Persechini A, Stull JT (1984) Phosphorylation kinetics of skeletal muscle myosin and the effect of phosphorylation on actomyosin adenosinetriphosphatase activity. Biochemistry 23:4144-4150

Petrache I, Birukov K, Zaiman AL, Crow MT, Deng H, Wadgaonkar R, Romer LH, Garcia JG (2003) Caspase-dependent cleavage of myosin light chain kinase (MLCK) is involved in TNF-alpha-mediated bovine pulmonary endothelial cell apoptosis. FASEB J 17:407-416

Pfitzer G (2001) Invited review: regulation of myosin phosphorylation in smooth muscle. J Appl Physiol 91:497-503

Poetter K, Jiang H, Hassanzadeh S, Master SR, Chang A, Dalakas MC, Rayment I, Sellers JR, Fananapazir L, Epstein ND (1996) Mutations in either the essential or regulatory light chains of myosin are associated with a rare myopathy in human heart and skeletal muscle. Nat Genet 13:63-69 
Previs MJ, Michalek AJ, Warshaw DM (2014) Molecular modulation of actomyosin function by cardiac myosin-binding protein $\mathrm{C}$. Pflugers Arch 466:439-444

Price KM, Littler WA, Cummins P (1980) Human atrial and ventricular myosin light-chains subunits in the adult and during development. Biochem J 191:571-580

Pulcastro HC, Awinda PO, Breithaupt JJ, Tanner BC (2016) Effects of myosin light chain phosphorylation on length-dependent myosin kinetics in skinned rat myocardium. Arch Biochem Biophys. doi:10.1016/j.abb.2015.12.014

Qi F, Ogawa K, Tokinaga Y, Uematsu N, Minonishi T, Hatano Y (2009) Volatile anesthetics inhibit angiotensin II-induced vascular contraction by modulating myosin light chain phosphatase inhibiting protein, CPI-17 and regulatory subunit, MYPT1 phosphorylation. Anesth Analg 109:412-417

Rajashree R, Blunt BC, Hofmann PA (2005) Modulation of myosin phosphatase targeting subunit and protein phosphatase 1 in the heart. Am J Physiol Heart Circ Physiol 289:H1736-H1743

Ratti J, Rostkova E, Gautel M, Pfuhl M (2011) Structure and interactions of myosin-binding protein $\mathrm{C}$ domain $\mathrm{C} 0$ : cardiac-specific regulation of myosin at its neck? J Biol Chem 286:12650-12658

Rayment I, Rypniewski WR, Schmidt-Base K, Smith R, Tomchick DR, Benning MM, Winkelmann DA, Wesenberg G, Holden HM (1993) Three-dimensional structure of myosin subfragment-1: a molecular motor. Science 261:50-58

Richardson JL, Kroger B, Hoeffken W, Sadler JE, Pereira P, Huber R, Bode W, Fuentes-Prior P (2000) Crystal structure of the human [alpha]-thrombin-haemadin complex: an exosite II-binding inhibitor. EMBO J 19:5650-5660

Riddick N, Ohtani K, Surks HK (2008) Targeting by myosin phosphatase-RhoA interacting protein mediates RhoA/ROCK regulation of myosin phosphatase. J Cell Biochem 103:1158-1170

Rosenfeld SS, Xing J, Cheung HC, Brown F, Kar S, Sweeney HL (1998) Structural and kinetic studies of phosphorylationdependent regulation in smooth muscle myosin. J Bio Chem 273:28682-28690

Ryder JW, Lau KS, Kamm KE, Stull JT (2007) Enhanced skeletal muscle contraction with myosin light chain phosphorylation by a calmodulin-sensing kinase. J Biol Chem 282:20447-20454

Sale DG (2002) Postactivation potentiation: role in human performance. Exerc Sport Sci Rev 30:138-143

Sanbe A, Fewell JG, Gulick J, Osinska H, Lorenz J, Hall DG, Murray LA, Kimball TR, Witt SA, Robbins J (1999) Abnormal cardiac structure and function in mice expressing nonphosphorylatable cardiac regulatory myosin light chain 2 . J Biol Chem 274:21085-21094

Sarkar S, Sreter FA, Gergely J (1971) Light chains of myosins from white, red, and cardiac muscles. Proc Natl Acad Sci USA 68:946-950

Satterwhite LL, Lohka MJ, Wilson KL, Scherson TY, Cisek LJ, Corden JL, Pollard TD (1992) Phosphorylation of myosin-II regulatory light chain by cyclin-p34cdc2: a mechanism for the timing of cytokinesis. J Cell Biol 118:595-605

Schulenberg B, Goodman TN, Aggeler R, Capaldi RA, Patton WF (2004) Characterization of dynamic and steady-state protein phosphorylation using a fluorescent phosphoprotein gel stain and mass spectrometry. Electrophoresis 25:2526-2532

Scruggs SB, Solaro RJ (2011) The significance of regulatory light chain phosphorylation in cardiac physiology. Arch Biochem Biophys 510:129-134

Scruggs SB, Hinken AC, Thawornkaiwong A, Robbins J, Walker LA, de Tombe PP, Geenen DL, Buttrick PM, Solaro RJ (2009) Ablation of ventricular myosin regulatory light chain phosphorylation in mice causes cardiac dysfunction in situ and affects neighboring myofilament protein phosphorylation. J Biol Chem 284:5097-5106
Scruggs SB, Reisdorph R, Armstrong ML, Warren CM, Reisdorph N, Solaro RJ, Buttrick PM (2010) A novel, in-solution separation of endogenous cardiac sarcomeric proteins and identification of distinct charged variants of regulatory light chain. Mol Cell Proteom 9:1804-1818

Seguchi O, Takashima S, Yamazaki S, Asakura M, Asano Y, Shintani Y, Wakeno M, Minamino T, Kondo H, Furukawa H, Nakamaru K, Naito A, Takahashi T, Ohtsuka T, Kawakami K, Isomura T, Kitamura S, Tomoike H, Mochizuki N, Kitakaze M (2007) A cardiac myosin light chain kinase regulates sarcomere assembly in the vertebrate heart. J Clin Invest 117:2812-2824

Seidman CE, Seidman JG (1998) Molecular genetic studies of familial hypertrophic cardiomyopathy. Basic Res Cardiol 93(Suppl 3):13-16

Sheikh F, Ouyang K, Campbell SG, Lyon RC, Chuang J, Fitzsimons D, Tangney J, Hidalgo CG, Chung CS, Cheng H, Dalton ND, Gu Y, Kasahara H, Ghassemian M, Omens JH, Peterson KL, Granzier HL, Moss RL, McCulloch AD, Chen J (2012) Mouse and computational models link Mlc2v dephosphorylation to altered myosin kinetics in early cardiac disease. J Clin Invest 122:1209-1221

Sheikh F, Lyon RC, Chen J (2015) Functions of myosin light chain-2 (MYL2) in cardiac muscle and disease. Gene 569:14-20

Silver PJ, Buja LM, Stull JT (1986) Frequency-dependent myosin light chain phosphorylation in isolated myocardium. J Mol Cell Cardiol 18:31-37

Smith IC, Huang J, Quadrilatero J, Tupling AR, Vandenboom R (2010) Posttetanic potentiation in mdx muscle. J Muscle Res Cell Motil 31:267-277

Sobieszek A, Jertschin P (1986) Urea-glycerol-acrylamide gel electrophoresis of acidic low molecular weight muscle proteins: rapid determination of myosin light chain phosphorylation in myosin, actomyosin and whole muscle samples. Electrophoresis 7:417-425

Somlyo AV (2007) Cyclic GMP regulation of myosin phosphatase: a new piece for the puzzle? Circ Res 101:645-647

Somlyo AP, Somlyo AV (2003) $\mathrm{Ca}^{2+}$ sensitivity of smooth muscle and nonmuscle myosin II: modulated by G proteins, kinases, and myosin phosphatase. Physiol Rev 83:1325-1358

Somlyo AV, Wang H, Choudhury N, Khromov AS, Majesky M, Owens GK, Somlyo AP (2004) Myosin light chain kinase knockout. J Muscle Res Cell Motil 25:241-242

Song W, Vikhorev PG, Kashyap MN, Rowlands C, Ferenczi MA, Woledge RC, MacLeod K, Marston S, Curtin NA (2013) Mechanical and energetic properties of papillary muscle from ACTC E99K transgenic mouse models of hypertrophic cardiomyopathy. Am J Physiol Heart Circ Physiol 304:H1513-H1524

Spudich JA (2001) The myosin swinging cross-bridge model. Nat Rev Mol Cell Biol 2:387-392

Steinberg TH (2009) Protein gel staining methods: an introduction and overview. Methods Enzymol 463:541-563

Stelzer JE, Patel JR, Moss RL (2006) Acceleration of stretch activation in murine myocardium due to phosphorylation of myosin regulatory light chain. J Gen Physiol 128:261-272

Stewart MA, Franks-Skiba K, Chen S, Cooke R (2010) Myosin ATP turnover rate is a mechanism involved in thermogenesis in resting skeletal muscle fibers. Proc Natl Acad Sci USA 107:430-435

Stull JT, Nunnally MH, Michnoff CH (1986) 4 Calmodulin-dependent protein kinases. Enzym 17:113-166

Stull JT, Kamm KE, Vandenboom R (2011) Myosin light chain kinase and the role of myosin light chain phosphorylation in skeletal muscle. Arch Biochem Biophys 510:120-128

Surks HK, Richards CT, Mendelsohn ME (2003) Myosin phosphatase-Rho interacting protein. A new member of the myosin 
phosphatase complex that directly binds RhoA. J Biol Chem 278:51484-51493

Surks HK, Riddick N, Ohtani K (2005) M-RIP targets myosin phosphatase to stress fibers to regulate myosin light chain phosphorylation in vascular smooth muscle cells. J Biol Chem 280:42543-42551

Sutherland C, Walsh MP (2012) Myosin regulatory light chain diphosphorylation slows relaxation of arterial smooth muscle. J Biol Chem 287:24064-24076

Sweeney HL, Stull JT (1990) Alteration of cross-bridge kinetics by myosin light chain phosphorylation in rabbit skeletal muscle: implications for regulation of actin-myosin interaction. Proc Natl Acad Sci USA 87:414-418

Sweeney HL, Bowman BF, Stull JT (1993) Myosin light chain phosphorylation in vertebrate striated muscle: regulation and function. Am J Physiol 264:C1085-C1095

Syamaladevi DP, Spudich JA, Sowdhamini R (2012) Structural and functional insights on the Myosin superfamily. Bioinform Biol Insights 6:11-21

Szczesna D (2003) Regulatory light chains of striated muscle myosin. Structure, function and malfunction. Curr Drug Targets Cardiovasc Haematol Disord 3:187-197

Szczesna D, Ghosh D, Li Q, Gomes AV, Guzman G, Arana C, Zhi G, Stull JT, Potter JD (2001) Familial hypertrophic cardiomyopathy mutations in the regulatory light chains of myosin affect their structure, $\mathrm{Ca}^{2+}$ binding, and phosphorylation. J Biol Chem 276:7086-7092

Szczesna D, Zhao J, Jones M, Zhi G, Stull J, Potter JD (2002) Phosphorylation of the regulatory light chains of myosin affects $\mathrm{Ca}^{2+}$ sensitivity of skeletal muscle contraction. J Appl Physiol 92:1661-1670

Takashima S (2009a) Phosphorylation of myosin regulatory light chain by myosin light chain kinase, and muscle contraction. Circ J 73:208-213

Takashima S (2009b) Phosphorylation of myosin regulatory light chain by myosin light chain kinase, and muscle contraction. Cir J 73:208-213

Takemoto K, Ishihara S, Mizutani T, Kawabata K, Haga H (2015) Compressive stress induces dephosphorylation of the myosin regulatory light chain via RhoA phosphorylation by the adenylyl cyclase/protein kinase A signaling pathway. PLoS One 10:e0117937

Tarigopula M, Davis RT 3rd, Mungai PT, Ryba DM, Wieczorek DF, Cowan CL, Violin JD, Wolska BM, Solaro RJ (2015) Cardiac myosin light chain phosphorylation and inotropic effects of a biased ligand, TRV120023, in a dilated cardiomyopathy model. Cardiovasc Res 107:226-234

Taylor KA, Feig M, Brooks CL 3rd, Fagnant PM, Lowey S, Trybus KM (2014) Role of the essential light chain in the activation of smooth muscle myosin by regulatory light chain phosphorylation. J Struct Biol 185:375-382

Tesi C, Colomo F, Nencini S, Piroddi N, Poggesi C (2000) The effect of inorganic phosphate on force generation in single myofibrils from rabbit skeletal muscle. Biophys J 78:3081-3092

Tesi C, Piroddi N, Colomo F, Poggesi C (2002) Relaxation kinetics following sudden $\mathrm{Ca}^{(2+)}$ reduction in single myofibrils from skeletal muscle. Biophys J 83:2142-2151

Toepfer C, Caorsi V, Kampourakis T, Sikkel MB, West TG, Leung MC, Al-Saud SA, MacLeod KT, Lyon AR, Marston SB, Sellers JR, Ferenczi MA (2013) Myosin regulatory light chain (RLC) phosphorylation change as a modulator of cardiac muscle contraction in disease. J Biol Chem 288:13446-13454

Tohtong R, Yamashita H, Graham M, Haeberle J, Simcox A, Maughan D (1995) Impairment of muscle function caused by mutations of phosphorylation sites in myosin regulatory light chain. Nature 374:650-653
Ushakov DS, Caorsi V, Ibanez-Garcia D, Manning HB, Konitsiotis AD, West TG, Dunsby C, French PM, Ferenczi MA (2011) Response of rigor cross-bridges to stretch detected by fluorescence lifetime imaging microscopy of myosin essential light chain in skeletal muscle fibers. J Biol Chem 286:842-850

van Der Velden J, Klein LJ, Zaremba R, Boontje NM, Huybregts MA, Stooker W, Eijsman L, de Jong JW, Visser CA, Visser FC, Stienen GJ (2001) Effects of calcium, inorganic phosphate, and $\mathrm{pH}$ on isometric force in single skinned cardiomyocytes from donor and failing human hearts. Circulation 104:1140-1146

Venema RC, Raynor RL, Noland TA Jr, Kuo JF (1993) Role of protein kinase $\mathrm{C}$ in the phosphorylation of cardiac myosin light chain 2. Biochem J 294(Pt 2):401-406

Verduyn SC, Zaremba R, van der Velden J, Stienen GJ (2007) Effects of contractile protein phosphorylation on force development in permeabilized rat cardiac myocytes. Basic Res Cardiol 102:476-487

Vikhorev PG, Song W, Wilkinson R, Copeland O, Messer AE, Ferenczi MA, Marston SB (2014) The dilated cardiomyopathycausing mutation ACTC E361G in cardiac muscle myofibrils specifically abolishes modulation of $\mathrm{Ca}^{(2+)}$ regulation by phosphorylation of troponin I. Biophys J 107:2369-2380

Walker LA, Fullerton DA, Buttrick PM (2013) Contractile protein phosphorylation predicts human heart disease phenotypes. Am J Physiol Heart Circ Physiol 304:H1644-H1650

Walsh MP (2011) Vascular smooth muscle myosin light chain diphosphorylation: mechanism, function, and pathological implications. IUBMB Life 63:987-1000

Wang H, Yang H, Shivalila CS, Dawlaty MM, Cheng AW, Zhang F, Jaenisch R (2013) One-step generation of mice carrying mutations in multiple genes by CRISPR/Cas-mediated genome engineering. Cell 153:910-918

Warren SA, Briggs LE, Zeng H, Chuang J, Chang EI, Terada R, Li M, Swanson MS, Lecker SH, Willis MS, Spinale FG, MaupinFurlowe J, McMullen JR, Moss RL, Kasahara H (2012) Myosin light chain phosphorylation is critical for adaptation to cardiac stress. Circulation 126:2575-2588

Weeds AG (1969) Light chains of myosin. Nature 223:1362-1364

Westwood SA, Perry SV (1981) The effect of adrenaline on the phosphorylation of the $\mathrm{P}$ light chain of myosin and troponin $\mathrm{I}$ in the perfused rabbit heart. Biochem J 197:185-193

Wilson DP, Susnjar M, Kiss E, Sutherland C, Walsh MP (2005) Thromboxane A2-induced contraction of rat caudal arterial smooth muscle involves activation of $\mathrm{Ca}^{2+}$ entry and $\mathrm{Ca}^{2+}$ sensitization: Rho-associated kinase-mediated phosphorylation of MYPT1 at Thr-855, but not Thr-697. Biochem J 389:763-774

Wirth A, Schroeter M, Kock-Hauser C, Manser E, Chalovich J, Lanerolle Pd, Pfitzer G (2003) Inhibition of contraction and myosin light chain phosphorylation in guinea-pig smooth muscle by p21-activated kinase 1. J Physiol 549:489-500

Yamakita Y, Yamashiro S, Matsumura F (1994) In vivo phosphorylation of regulatory light chain of myosin II during mitosis of cultured cells. J Cell Biol 124:129-137

Yang Z, Sweeney HL (1995) Restoration of phosphorylation-dependent regulation to the skeletal muscle myosin regulatory light chain. J Biol Chem 270:24646-24649

Yin F, Hoggatt AM, Zhou J, Herring BP (2006) 130-kDa smooth muscle myosin light chain kinase is transcribed from a CArGdependent, internal promoter within the mouse $M Y L K$ gene. Am J Physiol Cell Physiol 290:C1599-C1609

Yu D, Marchiando AM, Weber CR, Raleigh DR, Wang Y, Shen L, Turner JR (2010) MLCK-dependent exchange and actin binding region-dependent anchoring of ZO-1 regulate tight junction barrier function. Proc Natl Acad Sci USA 107:8237-8241

Yuan C-C, Muthu P, Kazmierczak K, Liang J, Huang W, Irving TC, Kanashiro-Takeuchi RM, Hare JM, Szczesna-Cordary D (2015) 
Constitutive phosphorylation of cardiac myosin regulatory light chain prevents development of hypertrophic cardiomyopathy in mice. Proc Natl Acad Sci USA 112:E4138-E4146

Zeng Q, Lagunoff D, Masaracchia R, Goeckeler Z, Cote G, Wysolmerski R (2000) Endothelial cell retraction is induced by PAK2 monophosphorylation of myosin II. J Cell Sci 113(Pt 3):471-482

Zhang WC, Peng YJ, Zhang GS, He WQ, Qiao YN, Dong YY, Gao YQ, Chen C, Zhang CH, Li W, Shen HH, Ning W, Kamm KE, Stull JT, Gao X, Zhu MS (2010) Myosin light chain kinase is necessary for tonic airway smooth muscle contraction. J Biol Chem 285:5522-5531

Zhao FQ, Craig R, Woodhead JL (2009) Head-head interaction characterizes the relaxed state of Limulus muscle myosin filaments. J Mol Biol 385:423-431

Zhi G, Ryder JW, Huang J, Ding P, Chen Y, Zhao Y, Kamm KE, Stull JT (2005) Myosin light chain kinase and myosin phosphorylation effect frequency-dependent potentiation of skeletal muscle contraction. Proc Natl Acad Sci USA 102:17519-17524 